\title{
Visual Delegates - Enhancing Player Perception by Visually Delegating Player Character Sensation
}

\author{
Sebastian Misztal \\ sebastian.misztal@hs-hannover.de \\ Interactive Reality Experiences \\ University of \\ Applied Sciences and Arts \\ Hannover, Germany
}

\author{
Guillermo Carbonell \\ guillermo.carbonell@hs-hannover.de \\ Interactive Reality Experiences \\ University of \\ Applied Sciences and Arts \\ Hannover, Germany
}

\author{
Jonas Schild \\ jonas.schild@hs-hannover.de \\ Interactive Reality Experiences \\ University of \\ Applied Sciences and Arts \\ Hannover, Germany
}

\begin{abstract}
While a player character in a game can experience all perceptual modalities, player senses are often limited, especially to the visual channel. As a result, many video games apply visual delegates that function as a substitution to enhance player perception and intensify the relation between player and player character. For instance, in first-person actions games, red colored edges on the screen layer visually inform the player of being hit and, to some extent, this visual feedback delegates the character's affect (i.e., pain) to the player's perception. Existing games apply such delegates in various forms. Yet, there is no systematic investigation or classification of these visual delegates resulting in a lack of understanding how to appropriately assign visual delegates to perceptual events in game design. Using a grounded theory-based approach, we systematically analyzed 102 character-centered video games. We collected 67 visual delegates and derived 12 associated groups of five basic perceptions. As a first, our work provides a systematic classification and collection that allows game designers to find appropriate visual delegates for character perceptions they want to trigger in players.
\end{abstract}

\section{CCS CONCEPTS}

- Software and its engineering $\rightarrow$ Interactive games; • Computing methodologies $\rightarrow$ Perception; $\bullet$ Human-centered computing $\rightarrow$ Human computer interaction (HCI).

\section{KEYWORDS}

video game analysis; visualization; perception; visual delegates; sensory delegates; character-centered video games; grounded theory

\section{ACM Reference Format:}

Sebastian Misztal, Guillermo Carbonell, and Jonas Schild. 2020. Visual Delegates - Enhancing Player Perception by Visually Delegating Player Character Sensation. In Proceedings of the Annual Symposium on Computer-Human Interaction in Play (CHI PLAY '20), November 2-4, 2020, Virtual Event, Canada. ACM, New York, NY, USA, 14 pages. https://doi.org/10.1145/3410404.3414238

Permission to make digital or hard copies of part or all of this work for personal or classroom use is granted without fee provided that copies are not made or distributed for profit or commercial advantage and that copies bear this notice and the full citation on the first page. Copyrights for third-party components of this work must be honored.

For all other uses, contact the owner/author(s).

CHI PLAY '20, November 2-4, 2020, Virtual Event, Canada

(c) 2020 Copyright held by the owner/author(s).

ACM ISBN 978-1-4503-8074-4/20/11.

https://doi.org/10.1145/3410404.3414238

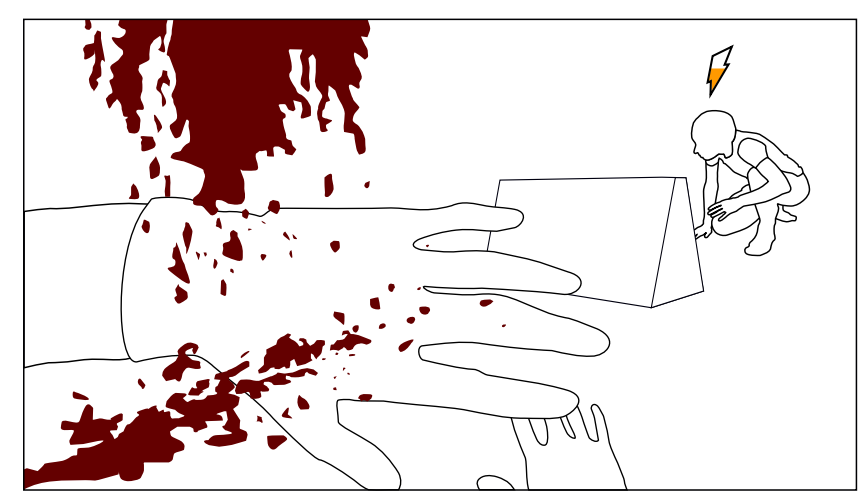

Figure 1: Examples of visual delegates. Hand posture and abstract depiction of blood on screen layer address player's perception of pain. Thunder symbol above other character's head shows level of detection and enhances sense of copresence.

\section{INTRODUCTION}

In neuroscience, sensory substitution examines how stimuli characteristic for one sensory modality (e.g., touch) can substitute stimuli for another sensory modality (e.g., vision) $[18,106]$. Comparable substitutions are applied in video games. For instance, while walking over a pipe in Mirror's Edge [50] (figure 5), the game world is visually tilted (what we call a visual delegate) and as a result, the player's sense of balance is addressed for a better understanding of the character's situation through the visual modality. The application of such substitutions of modalities is motivated by the limited capabilities of current output devices (e.g., displays, headphones or vibrating controllers), which can reliably address the player's perception primarily through visual, auditory and tactile modalities. Other senses (e.g., smell, taste, balance) remain unavailable in video games which is why game designers most often rely on visual effects to delegate other perceptions. However, the use of such visual delegates in games is often based on heuristics and common practice but not on profound evaluation or comprehension. What kind of perception can be triggered with what kind of visualization might be unclear because there is no natural or distinct mapping between a visual delegate and a related perception, which can confuse players. Moreover, these delegates have not yet been systematically recorded or compiled which can be problematic for 
some game designers who may lose track of them due to the huge quantity of visual delegates already applied in video games.

To address these problems, we analyzed character-centered video games $\left(\mathrm{CCVG}^{1}\right)$ of different art styles and genres. As part of our analysis, we collected relevant and representative visual delegates. We derived associated perceptions these delegates are triggering or enhancing to make the following contributions:

- a classification providing an overview of perceptions conveyed through visual delegates repeatedly applied in CCVG

- a collection containing associations between perceptions and visual delegates which can function as a tool for game designers to decide which visual delegate can be used to trigger what kind of perception

- a video game analysis improving the understanding of how visual delegates, addressing the player's perception, are applied in CCVG

During our analysis, we also discovered sensory delegates that are conveyed via other modalities (e.g., audio). In this paper, we focus on delegates that are transported visually because vision is the most dominant addressed modality in video games, not least because most humans absorb most of their information visually [112].

\section{RELATED WORK}

In this section, we first look at related visual techniques applied in (game) research that aim at enhancing player perception. We found several of the visual techniques presented here in a comparable form in our video game analysis. Secondly, we review related game analyses that use a grounded theory-based approach. We thirdly describe how graphical game interfaces host visual game elements to derive a concept for further categorization of visual delegates.

\subsection{Visual Techniques Enhancing Human Perception in (Game) Research}

We found visual techniques enhancing the human perception in (game) research in the context of perceiving an own virtual representation in form of an avatar and navigating in and experiencing a virtual environment. Visual filters were used to imitate age-related visual impairments $[16,172]$. Visual blur effects were used to simulate a stroke [122], to visualize electrosmog [63] and to focus attention for navigating in video games [83]. Glowing breadcrumb trails have been shown to function as a navigation assistance to develop a mental model of a game world [96]. Perception of depth and spatial awareness were investigated by using $\mathrm{x}$-ray vision [17] Visual feedback, e.g., optical flow field manipulation for self-motion illusion [27] was shown to have positive effects on human distance perception $[8,115]$. Perception of movement was investigated with a swaying camera [104]. Simulation of drunk driving in a kart racing game was studied by shading color, reducing contrast and using vignetting and fisheye view [171]. Visualizing a full avatar in firstperson perspective was shown to decrease errors made in distance perception $[114,128,134]$. Body-ownership and agency was investigated with humanoid and non-humanoid avatars with wings of a bat $[11,12,56]$ as well as zoologic avatars $[100,101]$ by using

${ }^{1} \mathrm{CCVG}$ refer to games in which the player's actions serve solely to control one player character, cf., [33] visuotactile feedback. To perceive the world from the view of a cat, a combination of distance blur, color transformation, luminance transformation and changing the user's perspective (lower visual eye height) was used [110]. By reducing the visual range and the spatial resolution, a mosquito's hunting behavior was imitated to be perceived by humans [148].

\subsection{Qualitative Methods to Analyze Video Games}

Drachen, Mirza-Babaei, and Nacke [45] collected methods for analyzing video games and especially their users. Some of the qualitative methods in their collection are: player observation [138], think-aloud protocol [99], heuristic evaluations [43, 126] and the rapid interactive test and evaluation method [113], which are generally suited for usability testing and to capture player experience, respectively. For their collection, Drachen, Mirza-Babaei, and Nacke [45] also included grounded theory [108], an approach to systematically collect and analyze qualitative data, especially text. According to Fernández-Vara [65], (video) games can be compared with text, since both have similarities in their meaning and cultural significance. Grounded theory was used by Brown and Cairns [26] to create a definition of immersion from the perspective of gamers. Kumari et al. [103] applied grounded theory to investigate player motivation caused by uncertainty. Allison et al. [10] examined a large set of video games to retrieve voice interaction design patterns in video and audio games. Similarly to our work, the authors applied a coding process, which is essential in grounded theory. Alharthi et al. [9] used a grounded theory-based approach with a coding process to identify mechanics, interfaces, and gameplay characteristics of idle games. The authors developed a taxonomy providing a common language which can be used by game designers and researchers to better discuss characteristics of idle games. Applying similar methodology, Wuertz et al. [175] retrieved awareness cues in collaborative video games. Awareness cues provide visual and/or auditory information, e.g., about the teammates' presence, identity, location, gaze, status, and task. The authors designed a framework for awareness cues as a tool, e.g., to help game designers to establish visual and/or auditory awareness between players. In several coding cycles, Toups et al. [156] applied thematic analysis to analyze video games in terms of cartography interfaces, i.e., maps which can be annotated and constructed by players.

\subsection{Visual Elements in Graphical Game Interfaces}

According to Schell [140], the virtual game interface contains virtual input elements (e.g., virtual buttons) and virtual output elements (e.g., score displays) which define the transformation of data between player and game. Fragoso [66] distinguishes between a material interface (hosting physical objects of the game world), an external interface (hosting elements which are independent of the representation of the game world), and a semiotic interface, i.e., a middle ground between the game world and the outside world, on the head-up display (HUD). The HUD is of great importance because it presents crucial game elements and it also contributes to the identification of games and their genres [109]. Fagerholt et al. [62] distinguish between game elements which are rendered in the 
game world, on a filter (e.g., gradually fading the image), or on an overlay, what others refer to as the HUD. Schild et al. [142] categorized game elements into implicit (functional information through design within the game world), explicit (information on an abstract layer), and referencing information (elements which are part of the HUD and reference objects inside the game world). Galloway [73] distinguishes between diegetic game elements which are part of the narrative game world and non-diegetic game elements which are external to the narrative world (also defined as extradiegetic [65]). Peacocke et al. [127] distinguish between diegetic (in-game) and HUD methods. Iacovides et al. [86] describe components which are visible to a player character in a video game as diegetic and components which are solely visible to a player as non-diegetic. Schild et al. [141] proposed and showcased the application of a graphical user interface (GUI) design space for games that emphasizes both the diegetic integration of GUI elements and their spatial positioning between player view and game world.

Oriented towards Schild et al. [141, 142], we decided to additionally differentiate between implicit and explicit visual delegates for our classification (see 3.3 Implicit and Explicit Visual Delegates). This differentiation is motivated by the study of Iacovides et al. [86] who compared a diegetic and a non-diegetic interface inside a first-person shooter game, showing that removal of non-diegetic elements can increase cognitive involvement and sense of control by expert players. We conclude that the different effects which diegetic compared to non-diegetic elements can produce in players may in turn affect the decision of game designers as to what type of elements to use, depending on what type of players to target, e.g., diegetic elements (or implicit visual delegates) for experts and non-diegetic elements (or explicit visual delegates) for novices.

\section{METHODOLOGY}

Based on related work, we describe how our classification process is applied and how video games were selected to be analyzed. After that we describe how we further categorized visual delegates regarding their representation to the players.

\subsection{Classification Procedure}

Our process of analyzing video games and generating a classification of perceptions delegated through visual effects is oriented towards grounded theory [77], a form of qualitative analysis best suited to collect and examine rich data sources, e.g., a large set of video games. Grounded theory can generally be applied by breaking down data with a coding process, followed by grouping and categorizing the data to build a theory behind the analyzed data [108] Our focus for the classification process was human perception and related relevant subjects in game research, such as presence, since the detection of these perceptions motivated us to conduct this analysis in the first place. Hence, we used open and selective coding iteratively to classify visual delegates into perceptions. Our classification, as well as the selection of games and genres, emerged during this iterative process.

We structured our classification process in three iterative steps: (1) acquisition, (2) analysis, and (3) evaluation. At the beginning of the first iteration, one game containing a visual delegate addressing a player's perception was selected (1). We analyzed the game (2) by playing it and by watching gameplay videos, i.e., Let's Plays, as they provide varying perspectives and insights by other players, contributing to objectification. We applied thinking aloud while playing and collected player's commentary from gameplay videos. For our analysis, we inspected a player character's ${ }^{2}$ action, investigated the related visual delegate, and then ascribed that delegate to a perception (class) the character experienced. A visual delegate can be assigned to more than one class if this delegate addresses more than one perception. When we found new perceptions, we gave them transitional names (open coding). In later iterations we watched out for similarities and recurring visual delegates to assign them to existing classes/perceptions (selective coding). When we found distinctions in the evaluation step (3), we decided to split a class (perception) into sub-classes (sub-perceptions). When we found overlying structures, according classes were downgraded into sub-classes and then composed to super-classes. After the game analysis and a grouping and reclassification step, an iteration ended. In the next iteration, we tried to select a game approving and a game disproving the previous classification (see also 3.2 Selection of Games). When this was not possible, we selected a game from which we assumed that it would use similar visual delegates and a game that would use different visual delegates, compared to the game(s) from the previous iteration. The whole iteration process terminated (or saturated) when no new games were found leading to significant (sub-)classification changes.

Four researchers with high game expertise (playing, development, analysis, teaching) were involved in this process. Most of the coding process was conducted by two of the four persons. The coding was examined by two additional senior researchers with expertise in psychology, computer science, and game research as well as commercial game development.

\subsection{Selection of Games}

We decided to examine CCVG, since we noticed that this type of games uses a large amount of visual delegates between player and player character. At the beginning, to select a game, we used own game libraries. To find further CCVG, we used online search engines and browsed the Steam and PlayStation store. We used keywords connected to genres of CCVG (e.g., open world, exploration, action, adventure, shooter) and keywords emerged during our coding process (e.g., from visual delegates or extracted perceptions). Before analyzing games that were unknown to us, we first watched video reviews to assess whether these games were qualified. When we found an appropriate game to analyze, we also looked out for comparable games from the same developers and publishers. When we watched gameplay videos (especially on YouTube) besides playing games, we also followed recommendations from the video platform if the recommended games contained relevant visual delegates.

\subsection{Implicit and Explicit Visual Delegates}

To refine our collection of visual delegates, we differentiated between implicit and explicit delegates (cf., Schild et al. [141, 142]). We considered implicit delegates perceivable by the player and the player character, comparable to diegetic game elements. Implicit

\footnotetext{
${ }^{2}$ We use the term "(player) character" for all types of characters which are controlled by the player including avatars (configurable characters), cf., [65]
} 
delegates are located in the game world providing complex information which have to be combined or derived by the player to make sense of it. Implicit delegates use interactive concepts, e.g., altering the camera's angle or physical hints from the environment. Explicit delegates are solely perceivable by the player with similarities to non-diegetic game elements. Explicit delegates typically consist of information based upon graphics and text, e.g., a health bar or a textual hint, mostly hosted outside the game world. Usually displayed on the virtual interface, we consider explicit delegates as abstractions of complex information, condensed to accessible perceptual information.

\section{RESULTS}

We analyzed 102 CCVG from the years 1992 to 2019 with different art styles, e.g., naturalistic, minimalist, comic or cel shading. The games we analyzed belong to the genres action, adventure, exploration, fighting, flight simulation, horror, puzzle, racing, roleplaying, shooter, sports, stealth and story. During our video game analysis, we collected 67 visual delegate types (35 implicit, 32 explicit). We grouped these visual delegates into 12 associated perception sub-classes which are part of five super-classes, which we identified as five basic dimensions of perceptions repeatedly occurring in CCVG. These five associated perceptions are: presence, embodiment, proprioception, movement and health. A classification illustrating these five perceptions and corresponding sub-perceptions is depicted in figure 2.

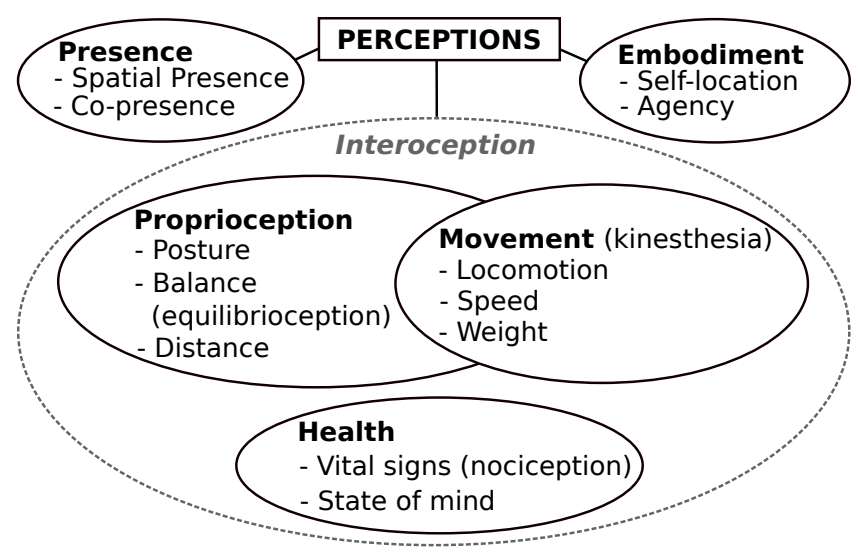

Figure 2: Classification of the five basic perceptions: presence, embodiment, proprioception, movement (part of proprioception), health and corresponding sub-perceptions.

Each of the following subsection covers one of the five basic perceptions we identified. In each subsection we first define the according perception to clarify its general meaning. Then, we describe how corresponding sub-perceptions are applied in CCVG and what types of visual delegate were used to address these sub-perceptions. We further distinguish between implicit and explicit visual delegates. For a better overview, we summarize these delegate types with corresponding sub-perceptions in table 1-5. A few visual delegates we found address more than one perception. We mark these delegates in the tables by the first three letters of the perception they also address, e.g., ${ }^{\mathrm{PRE}}$ for presence. The tables also list examples of CCVG in which we found and analyzed the listed delegates. Representative implicit and explicit visual delegates are illustrated in figure 3-7.

\subsection{Presence}

Our analysis revealed visual delegates designed to engage players in two dimensions of the experience of presence, i.e., spatial presence and co-presence (a dimension of social presence). The general term of presence can be considered as the experience of being in a virtual environment, even though being physically situated somewhere else $[90,174]$. Spatial presence is established through the experience of being physically located in a virtual environment [90] or perceiving virtual objects as real objects [105]. In the context of video games, spatial presence can shortly be described as "being there in electronic games" [150]. Social presence can be described as "being with others in electronic games" [150] and being socially connected to these other actors [23, 81, 143], regardless whether the other social actors are controlled by humans or computer algorithms [125]. Social presence consists of several dimensions [22], of which co-presence is the most common in video games [150]. Copresence is defined as the sensory awareness of an embodied other, including the other's body and actions [23, 78]. Co-presence can additionally comprise a mutual awareness, i.e., when the embodied other is aware of the player character $[22,78]$.

4.1.1 Spatial Presence (implicit). The player's perspective (thirdand first-person) is a crucial factor for improving the perception of being physically situated in a game [150], which is applied in a variety of CCVG $[36,69,75,95,120,166]$. Displaying the player character's shadow can further contribute to enhance spatial presence. Before providing shadows with more details, outlining the player character's posture and equipment, shadows in prior video games such as Codename Eagle [131] consisted of rudimentary dark circular disks to give the player a plausible feeling of the character to be present in the virtual world. A few video games that do not include a depiction of the player character's body still depict the character's shadow, cf., The Witness [155].

When the player character is peeking through an opening, the shape of the cutout can give the player an implicit understanding of being present at a certain location in the game world. When looking through a keyhole in Dishonored 2 [15] the screen is colored in black with a cutout of a simplified shape of a key. The same can be discovered in Grand Theft Auto V [136] or Bloodborne [69] where the view through a monocular is displayed as a cutout in form of a circle on a black screen. The border of the round cutout itself has a vignetting, slightly blurry and coated with a filter. By wearing a mask or a helmet, the player implicitly perceives the feeling of a physical border between the player character and the rest of the environment [53]. In Subnautica [167] and BioShock [3], the view is framed with the seal and a faceplate of a diving mask to augment the sensation of being underwater. In Metroid Prime [133], the character wears a powered exoskeleton with a helmet. The view is framed by straight vertical and curved horizontal lines indicating a curved visor. Further restrictions of the view can enhance the perception of being in the game world, such as dirt hitting the character in form of dark, irregular scattered chunks displayed in the player's 
field of view [53]. In Crysis [37] climate characteristics of the game world are perceived through moisture, wetness and feeling of cold by depictions of raindrops and spreading frost on the faceplate of the player character's helmet.

4.1.2 Spatial Presence (explicit). The sense of spatial presence can be addressed by providing the player a mental model of the environment. Compasses in the early Medal of Honor games [1, 47, 48] provide the player an explicit but aging navigation technique through the virtual world. When using a vehicle in Grand Theft Auto IV [135], a mini map functions as a GPS navigation by marking the way to the desired waypoint by coloring the shortest path. Mods (modifications) from the gamer community are guiding the player with 2D arrows pointing to the right direction. BioShock 2 [4] uses a spinning 3D arrow. In recent video games, symbols, illustrating the location of a waypoint, are translated from 3D world to the 2D virtual interface. Left Alive [146] depicts a waypoint with a red exclamation point in a rectangle on the HUD.

4.1.3 Co-presence (implicit). Perceiving presence of other characters can be derived from objects these characters are dropping, excessively applied in the Borderlands series, cf., [2, 75]. Friendly companions can address the perception of co-presence by being constantly active and walking around in the player's field of view, e.g., a friend guiding the way through the game world in Uncharted: Drake's Fortune [119] or a dog in Far Cry 5 [166].

4.1.4 Co-presence (explicit). Abstract symbols marking dropped items (e.g., an exclamation point for grenades) and an arrow head pointing at its direction can induce the sense of co-presence [40, 53]. In Delta Force: Black Hawk Down [124] and Medal of Honor: Underground [48], hitting projectiles inform that others are present with quick flashing sectors on a map or a compass on the HUD, respectively. Half-Life [168] indicates the direction of impact with four red trapezoids on the HUD for left, right, up and down. More recent games $[25,29,146]$ visualize the direction of impact through red colored screen edges or with a red curved arrow in the middle range of the HUD [53, 74, 80,146, 157, 170], partly supported with a quick red flash screen [28]. Dishonored 2 [15] uses a thunder symbol over the character's head which turns red if the other character detects the player character (figure 1). Prey [85] uses a red curved arrow, looking like a curly bracket, pointing to the direction of the opponent. In the Far Cry series [162-164, 166] the curved arrow changes its color depending on whether the player character is detected by other opponents (figure 3). In The Forest [153], an eye symbol on the HUD indicates how easily the character can be spotted by others. The Last of Us [120] and Left Alive [146] provide the player with a sixth sense by making marked opponents visible through obstacles (figure 3). Rise of the Tomb Raider [36], Far Cry Primal [164] and Assassin's Creed II [161] use a special visual mode which colors the environment gray and highlights interactive objects or subjects. This mode is called survival instinct, hunter vision or eagle vision, respectively, and can also address the sense of agency. In Sniper: Ghost Warrior 2 [32] other characters are annotated with a symbol, showing the distance and the position of the character, e.g., two arrows up to indicate that the other character is located above the player character. Far Cry 5 [166] provides a dynamic presence bar in the upper area on the HUD functioning as an echo sounding with

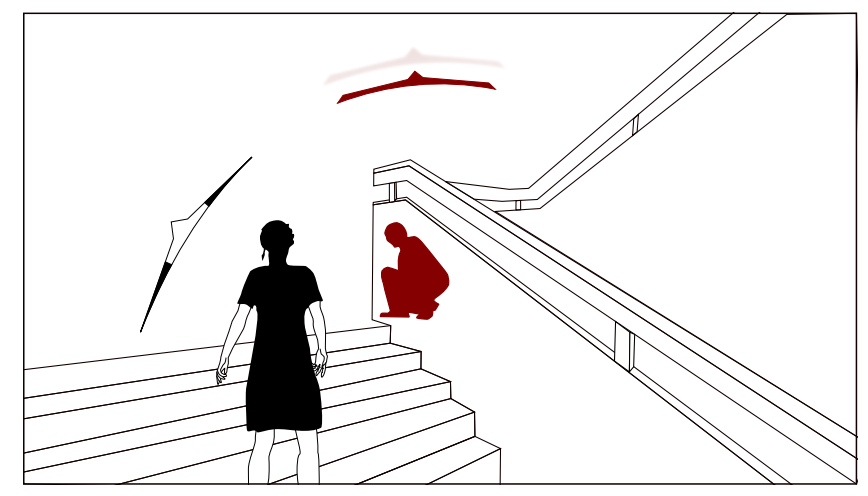

Figure 3: Examples of visual delegates addressing perception of presence. Co-presence (explicit): curved arrows point to other entities, animation of curved arrows visualize the level of awareness the other entity has towards the player character; $x$-ray vision allows to see other entities through objects to perceive their presence. Spatial Presence (implicit): besides first-person perspective, third-person perspective can also enhance perception of being in the game.

Table 1: Visual delegates addressing sense of presence and exemplary video games using these delegates. Additional use in other perceptions is marked with EMB for embodiment, PRO for proprioception, and HEA for health.

\begin{tabular}{|c|c|}
\hline Visual Delegate (Presence) & Games \\
\hline \multicolumn{2}{|c|}{ Spatial Presence (implicit) } \\
\hline $1^{\text {st }} \mathrm{PP} / 3^{\text {rd }} \mathrm{PP}$ (EMB) & {$[36,69,95,120]$} \\
\hline Shadows of player character $(\mathrm{PRO})$ & {$[39,131,155]$} \\
\hline Narrowed view (e.g., keyhole, helmet) & {$[15,69,133,167]$} \\
\hline Dirt from surrounding in FOV & {$[53]$} \\
\hline Frost and rain drops of faceplate & [37] \\
\hline \multicolumn{2}{|c|}{ Spatial Presence (explicit) } \\
\hline Navigation (compass, mini map, GPS) & {$[1,47,48,135]$} \\
\hline Warning symbol (exclamation point) & {$[146]$} \\
\hline $2 \mathrm{D}$ and $3 \mathrm{D}$ arrow for navigation & {$[3,4,135]$} \\
\hline \multicolumn{2}{|l|}{ Co-presence (implicit) } \\
\hline $\begin{array}{l}\text { Dropped item from another entity } \\
\text { Companion }\end{array}$ & $\begin{array}{l}{[2,75]} \\
{[119,166]}\end{array}$ \\
\hline \multicolumn{2}{|c|}{ Co-presence (explicit) } \\
\hline Symbol of dropped items on HUD & {$[40,53]$} \\
\hline Partly colored mini map/compass & {$[48,124]$} \\
\hline (Animated) curved arrow & {$[74,85,166,170]$} \\
\hline Colored screen edges (HEA) & {$[25,29,146]$} \\
\hline Filling thunder over opponent's head & {$[15]$} \\
\hline Eye symbol for visibility & {$[153]$} \\
\hline $\mathrm{X}$-ray vision with silhouette & {$[20,120,146]$} \\
\hline Survival/hunter/eagle vision (EMB) & {$[36,161,164]$} \\
\hline Symbol for distance and position & {$[32]$} \\
\hline Presence bar & {$[166]$} \\
\hline
\end{tabular}


an integrated compass scanning the immediate environment and illustrating objects and characters of interest with small abstract symbols.

\subsection{Embodiment}

Embodiment can be considered as the experience of having and using a body [24]. The sense of embodiment consists of the sense of self-location, the sense of agency and the sense of body ownership [98]. The sense of self-location is the spatial experience of being inside a body or an avatar, not inside a world, different from experiencing presence [107]. The sense of agency combines the experience of action, control and intention referring to the sense that the player is the one causing an action [72]. The sense of body ownership has a possessive nature. It refers to one's self-attribution of a body. During our video game analysis, we often detected selflocation and agency of the three dimensions of embodiment.

4.2.1 Self-Location (implicit). Slipping into the virtual body of the player character can address the player's sense of self-location, e.g., by perceiving the game world from first-person perspective. In Among the Sleep [102] the player slips into the body of a toddler discovering the world from a lower perspective. Small hands and arms intensify the perception of being located in a child. At the beginning of the game, an eyelid movement from first-person perspective gives the impression of waking up. Aliens vs. Predator [130] alters the player's sight by looking through a night-vision device when slipping into the role of the predator. The experience of slipping into the character's body can be extended by displaying the character's limbs. When looking straight ahead in BioShock [3] or Deus Ex: Mankind Divided [59], players can see the hands and in some cases the forearm of the player character. Thief [58] displays the character's hands only when interacting with an object or when trying to keep balance. Video games referred to as walking simulators with the purpose to explore the environment focussing on experiencing a story, tend to leave out the player character's hands and arms to concentrate on the narrative due to the rarely occurring manual interaction, cf., Gone Home [154] or Ether One [173]. Omitting depictions of the character's body from first-person perspective can lead to the impression that the character hovers above the ground as in Antichamber [41] which can disrupt the sense of self-location.

4.2.2 Self-Location (explicit). Doom [88] and the racing game Carmageddon [147] portray the head of the character on the HUD and depict the character's facial expressions matching the simultaneous reactions of the character, e.g., mimicking inflicted pain through the facial expressions when getting hurt. Without these depictions, the character's facial expression would remain unnoticeable for the player.

4.2.3 Agency (implicit). When changing from walking to hand mode (for grabbing) in Octodad [42], the perspective changes from third-person to almost first-person, depending on the interaction. The body of the player character is illustrated semi-transparently to focus on the grabbing. Apex Construct [64] focuses the camera specifically on the character's interaction when drawing a bow. Changing the posture of the character's limbs can further address the player's sense of agency. A changing posture of the character's

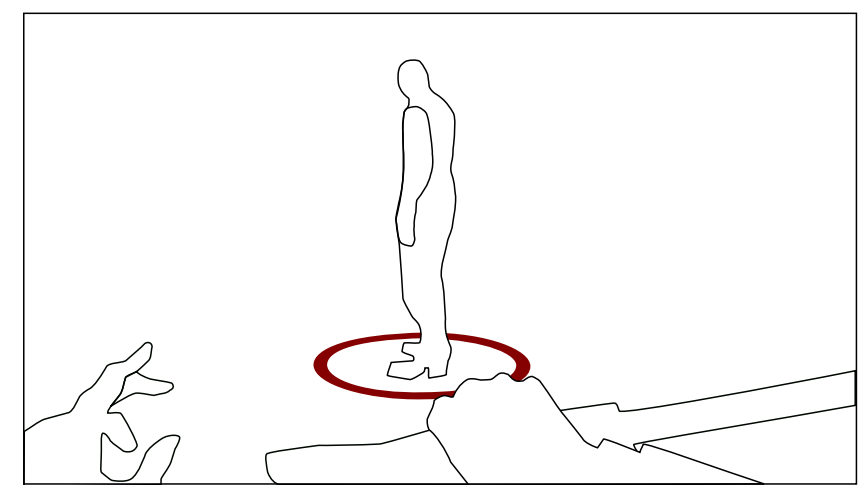

Figure 4: Examples of visual delegates addressing the perception of embodiment. Agency (implicit): changing posture of arms indicates possible attacking act. Agency (explicit): circle around other character indicates interaction.

Table 2: Visual delegates addressing sense of embodiment and exemplary video games using these delegates. Additional use in other perceptions is marked with PRE for presence and PRO for proprioception.

\begin{tabular}{|c|c|}
\hline Visual Delegate (Embodiment) & Games \\
\hline \multicolumn{2}{|l|}{ Self-Location (implicit) } \\
\hline First-person perspective ${ }^{(\mathrm{PRE})}$ & {$[2,95,166]$} \\
\hline Lower/higher perspective & {$[102]$} \\
\hline Eye lit movement in $1^{\text {st }} \mathrm{PP}$ & {$[55,102]$} \\
\hline Night vision & {$[130]$} \\
\hline Body depiction (limbs, torso) & {$[21,31,102]$} \\
\hline \multicolumn{2}{|l|}{ Self-Location (explicit) } \\
\hline Head depiction on HUD & {$[88,147]$} \\
\hline \multicolumn{2}{|l|}{ Agency (implicit) } \\
\hline Perspective change $\left(1^{\text {st }} \mathrm{PP}\right.$ to $\left.3^{\text {rd }} \mathrm{PP}\right){ }^{(\mathrm{PRO})}$ & {$[42,57,75]$} \\
\hline Focusing the interaction & {$[64]$} \\
\hline Changing limb posture & {$[15,50,80]$} \\
\hline \multicolumn{2}{|l|}{ Agency (explicit) } \\
\hline Text display & {$[21]$} \\
\hline Outline/entity accentuated with circle & {$[67,165]$} \\
\hline Contextual crosshair ${ }^{(\mathrm{PRO})}$ & {$[67]$} \\
\hline Symbol for possible/anticipating action & {$[14,165]$} \\
\hline Survival/hunter/eagle vision $(\mathrm{PRE})$ & {$[36,161,164]$} \\
\hline
\end{tabular}

arms in Dishonored 2 [15] indicates an attack (figure 4). In RICO [80] the character's posture changes according to the action performed, e.g., slightly but distinctive different movements for kicking doors or defeating opponents. Similar animations for similar interactions are applied in Mirror's Edge [50].

4.2.4 Agency (explicit). Agency can be supported by highlighting interactive objects or entities. The Elder Scrolls V: Skyrim [21] provides textual information if the crosshair is targeting an interactive object. In Amnesia: The Dark Descent [67], objects are outlined if 
they are interactive. Additionally, the crosshair changes the symbol to a grabbing hand. For Honor [165] visualizes a circle around opponents to indicate possible interaction (figure 4). Arrows in the HUD point to the direction of an anticipated attack. In Dishonored [14], symbols on the HUD illustrate possibilities of interaction, e.g., a symbol of a climbing person appears if the character reaches an interaction point for climbing.

\subsection{Proprioception}

Proprioception is part of interoception [13], which can be considered as "the sense of the physiological condition of the entire body" [34]. Interoception describes how a mapping of the body's internal landscape is provided by processing senses from inside the body [97]. Proprioception is the (spatial) sensation of body position, absent from conscious perception [111, 159]. Proprioception also gives humans information about muscle tension and is closely linked to kinesthesia, sense of movement [19, 44]. Equilibrioception (sense of balance) is also part of proprioception [129]. During our game analysis, we found visual delegates associated with three sub-categories of proprioception, i.e., posture, balance and distance.

4.3.1 Posture (implicit). In CCVG, three different body postures occur: standing, crouching, and lying. In first-person games, the body posture can be implied by comparing the own perspective to the position (vertical height) of objects and other characters in the environment $[25,52]$. A standing position can be implied when using a point of view, crouching when using a low-angel view, and lying when using a worm's-eye view. When looking down, stretched legs indicate a standing posture [116, 151]. Reflections of the character's body in puddles and mirrors [6], dynamic shadows [37], and changing from first- to third-person perspective can further reveal the player character's posture. In Deus Ex: Human Revolution [57] the perspective changes from first- to third-person when the player character is crouching behind an object to switch to a stealth posture or when the character is climbing a ladder. In Borderlands [75] or Halo 4 [5] the perspective changes from firstto third-person when the player character is entering a vehicle. When this happens too abrupt, the change of perspective can also be perceived as an interruption, cf., Project I.G.I. [94]. Changing the perspective can also be used to transport a sense of agency to the player.

4.3.2 Posture (explicit). The player character's posture is often depicted in little symbols of a lying, a crouching or a standing person on the HUD, cf., [54, 158, 166].

4.3.3 Balance (implicit). Far Cry 5 [166] and Mirror's Edge [50] roll the view camera at a certain angle when the player character is climbing a tower or balancing over a pipe (figure 5), respectively. Rolling the camera generates a tilted view of the environment and can replace the missing vestibular system in a video game to a certain extent. Half-stretched arms indicate that the player character is trying to create counterbalance (figure 5).

4.3.4 Balance (explicit). Tony Hawk's Pro Skater 3 [121] displays an arrow on a balance bar on the HUD while grinding (figure 5). The arrow indicates the direction the player character would fall if no countermovement was performed. Aliens vs. Predator [130]

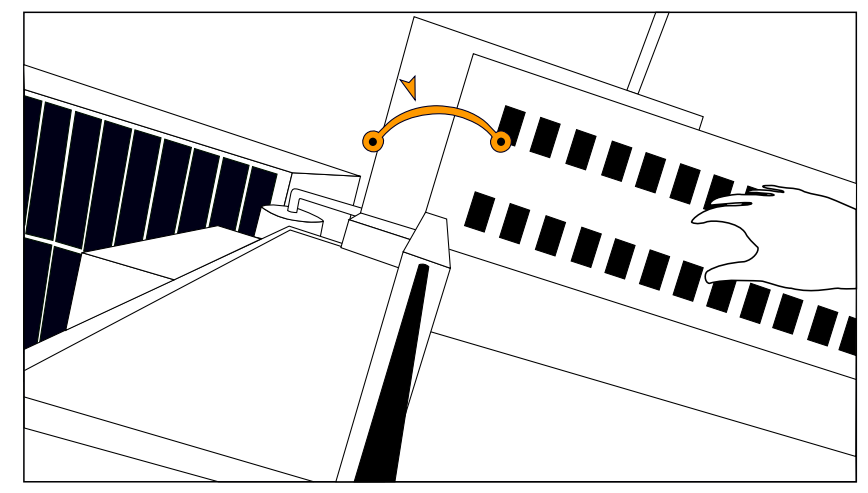

Figure 5: Examples of visual delegates addressing proprioception. Balance (implicit): tilted view addresses the player's sense of equilibrium; hand posture visualizes the player character's attempt to keep balance. Balance (explicit): balance bar on the HUD depicts degree of disequilibrium.

Table 3: Visual delegates addressing proprioception and exemplary video games using these delegates. Additional use in other perceptions is marked with PRE for presence, EMB for embodiment, and HEA for health.

\begin{tabular}{|c|c|}
\hline Visual Delegate (Proprioception) & Games \\
\hline \multicolumn{2}{|l|}{ Posture (implicit) } \\
\hline Translated/pitched view & {$[25,52]$} \\
\hline Interactive shadows/reflection of body (PRE) & {$[6,37]$} \\
\hline Illustrated limbs when looking down & {$[116,151]$} \\
\hline Perspective change ( $1^{\text {st }} \mathrm{PP}$ to $\left.3^{\text {rd }} \mathrm{PP}\right)(\mathrm{EMB})$ & {$[5,57,75]$} \\
\hline \multicolumn{2}{|l|}{ Posture (explicit) } \\
\hline Symbol of body posture & {$[54,158,166]$} \\
\hline \multicolumn{2}{|l|}{ Balance (implicit) } \\
\hline Tilted view ${ }^{(\mathrm{HEA})}$ & {$[50,166]$} \\
\hline Stretched arms for counterbalance & {$[50]$} \\
\hline \multicolumn{2}{|l|}{ Balance (explicit) } \\
\hline Balance bar & {$[121]$} \\
\hline Contextual crosshair (EMB) & {$[130]$} \\
\hline \multicolumn{2}{|l|}{ Distance (implicit) } \\
\hline Changing hand pose & {$[50]$} \\
\hline Colored objects in game world & {$[50,161]$} \\
\hline \multicolumn{2}{|l|}{ Distance (explicit) } \\
\hline Assisting jumping bar & [79] \\
\hline
\end{tabular}

supports the vestibular perception with a contextual crosshair. The player character (in the role of an alien) can climb walls and ceilings which can lead to orientation loss for the player. To minimize this loss, the crosshair - depicted with an arrow - dynamically points to the floor.

4.3.5 Distance (implicit). Mirror's Edge [50] addresses distance perception by changing the pose of the player character's hands. When standing near to an object, e.g., a fence, the hands are automatically 
pulled to the body with fingers spread and pointing upwards like defending the body from the near object. Enhancing the perception of distance to an object far away, e.g., another building, the character's arms are stretched out when performing a jump as if the character wanted to reach the distant object with the hands. In addition, certain objects are colored red to indicate areas from which a far jump can be triggered. Assassin's Creed II [161] marks certain jumping spots in a similar way.

4.3.6 Distance (explicit). Signifying a good moment to jump from one position to another, Bionic Commando [79] uses an interface element which consists of two short converging lines in the center of the HUD to explicitly assist the player while swinging from platform to platform. This jumping assistance helps to estimate and perceive distances.

\subsection{Movement}

The sense of movement (kinesthesia, part of proprioception) can be defined as a complex endowment helping humans to become familiar with the position and movements of their limbs. In addition, kinesthesia allows humans to judge weight and resistance [19] During our classification process, we decided to create a separate class for movement besides proprioception, because of its high occurrence in video games with the sub-classes locomotion, speed and weight.

4.4.1 Locomotion (implicit). Locomotion can be perceived through a visual flow effect where the environment seems to move in opposite direction to the moving direction of the player character. A swaying or shaky camera from first-person perspective can give the player a supplementary indication of a movement trying to imitate natural (non rectilinear) walking. In Wolfenstein $3 D$ [87] the player camera follows an even path in walking direction without further transformations. Doom [88] uses a swaying camera. In addition, the weapon is swaying horizontally from left to right.

4.4.2 Locomotion (explicit). In Katamari Damacy [118], a second representation of the player character is displayed on the HUD imitating the meditated movements of the character.

4.4.3 Speed (implicit). In Borderlands: The Pre-Sequel [2] or Battlefield 3 [52], running is indicated through the position of the items in the player character's hands. Running player characters point the weapon at the sky or near to the player character's body. The weapon is swaying faster while running when compared to walking (figure 6). In Dishonored [14], the alignment of the item in the characters' hands changes when the character is sneaking. A tunnel vision combined with a motion blur effect near to the edges of the field of view is used in Mirror's Edge [50] and Dishonored 2 [15] to indicate a certain speed and to set the player's focus to the running direction.

4.4.4 Speed (explicit). Racing games such as Need for Speed II [49] or Driveclub [60] enhance the perception of speed through a speedometer. As a non racing game, Half-Live 2 [169] similarly provides a sprint bar with discrete steps. A stamina bar in Dark Souls 2 [68] and Bloodborne [69] decreases faster, the faster the character is moving. Changing skills in Crysis [37] lead to changing colors of the player character's gloves (yellow for speed). Sprint

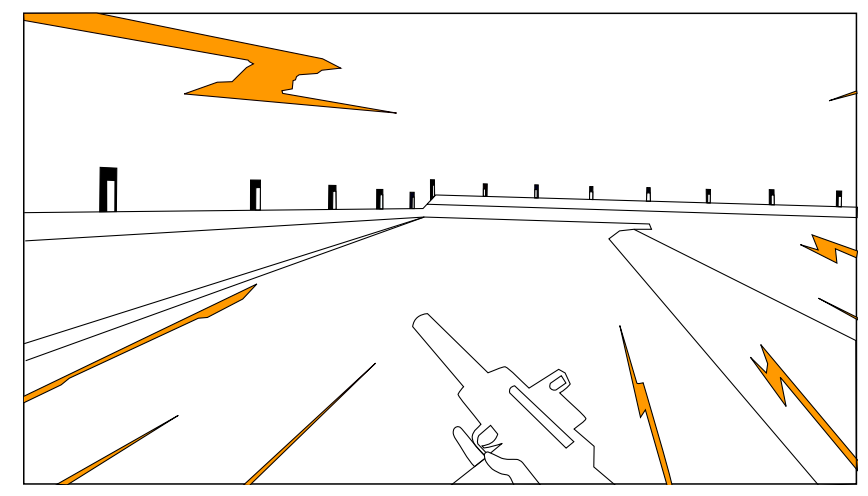

Figure 6: Examples of visual delegates addressing the perception of movement. Speed (implicit): fast swaying item in hand of player character indicates running. Speed (explicit): flashes pointing to the center of field of view while running.

Table 4: Visual delegates addressing sense of movement and exemplary video games using these delegates. Additional use in other sub-perceptions is marked with MOV.

\begin{tabular}{|c|c|}
\hline Visual Delegate (Movement) & Games \\
\hline \multicolumn{2}{|c|}{ Locomotion (implicit) } \\
\hline Visual flow effect & {$[50,87,89]$} \\
\hline Swaying items/shaky camera & {$[89,166]$} \\
\hline \multicolumn{2}{|c|}{ Locomotion (explicit) } \\
\hline Locomotion depiction on HUD & {$[118]$} \\
\hline \multicolumn{2}{|l|}{ Speed (implicit) } \\
\hline Faster swaying items & {$[52,75]$} \\
\hline Changing pose of character's hands & {$[14]$} \\
\hline Motion blur in tunnel vision & {$[15,50]$} \\
\hline \multicolumn{2}{|l|}{ Speed (explicit) } \\
\hline Speed/sprint/stamina bar ${ }^{(\mathrm{MOV})}$ & {$[49,60,68,69,169]$} \\
\hline Color-coded speed mode & {$[37]$} \\
\hline Speed flashes/stripes near character & {$[145,149]$} \\
\hline \multicolumn{2}{|l|}{ Weight (implicit) } \\
\hline Decreasing speed & {$[82,166]$} \\
\hline Superimposed view & {$[14,166]$} \\
\hline \multicolumn{2}{|l|}{ Weight (explicit) } \\
\hline Weight to be carried in menu & {$[21,68]$} \\
\hline Stamina/strength bar (MOV) & {$[21,68,139]$} \\
\hline Text/button for actions & {$[166]$} \\
\hline
\end{tabular}

Vector [149] uses orange-colored sprint lines pointing from the edges to the center of the field of view (figure 6). In Absolver [145] fast attacks are visually supplemented with short white stripes near the character in the direction of movement.

4.4.5 Weight (implicit). Dishonored [14], Far Cry 5 [166], and Counter-Strike: Global Offensive [82] reduce the speed of movement noticeably when heavier items are selected which either depends on the items the player can see from first-person perspective (i.e., items holding in the hand of the player character) or on the items the 
player can not see (i.e., items in the virtual backpack of the player character). In addition, part of the field of view is superimposed with the carried items.

4.4.6 Weight (explicit). Dark Souls II [68] and The Elder Scrolls V: Skyrim [21] provide weight information in the game menu in textual form. Shadow of the Colossus [139] depicts a strength or stamina bar in form of a colored circular disk. While carrying a body in Far Cry 5 [166], a textual hint and a depiction of the controller button which should be used to drop the body are displayed on the HUD.

\subsection{Health}

Nociception (a dimension of interoception) can be defined as the detection of painful stimuli [13, 132]. During our classification process we created a health-class and distinguished between vital signs (nociception) and state of mind.

4.5.1 Vital Signs (implicit). A lowered player camera showing the world from worm's-eye view can indicate the death of a character from first-person perspective [92]. Being wounded in Rust [61], shortly before the death of the player character, the character's legs and a protecting hand pose in a lying position indicate a collision or an attack (figure 7). A tilted view (player camera is rolled) implies disorientation which can be enhanced by a blur effect in the peripheral view [52, 93]. In Red Dead Redemption 2 [137] chromatic aberration and color grading effects are used to visually accentuate that the player character suffers from tuberculosis. Bad health conditions can be indicated with a tunnel vision or vignetting with red screen edges spreading to the center of the field of view [91, 146]. In Destiny 2 [29], a semi-transparent dust is restricting the view. Left 4 Dead [170] uses the same effect after taking adrenaline pills. Dark vignetting in War Thunder [71] expands to a dark screen indicating a loss of consciousness and fatigue to total unconsciousness. Since games started to refrain from using medical packs, players are used to implicit health visualizations which disappear after a short time when the player character regenerates health. After being hit in Subnautica [167] the faceplate of the player character's diving mask gets cracks which disappear after some time by slowly fading out. This process addresses health perception in a way that not only the player character's body regenerates - which is a natural process even if the short duration in games is unrealistic - but also objects the player character is wearing. Crysis 2 [38] uses a related implicit delegate with explicit content where a powered suit provides a regenerating armor which is visualized from first-person perspective with a hexagonal mesh in peripheral view.

4.5.2 Vital Signs (explicit). Health bars - plain or extended with additional information, e.g., a percentage display - are common game elements to delegate perception of pain from player character to player $[1,47,48]$. More recent CCVG still use classical health bars in combination with red colored edges on the HUD $[144,166]$ The Forest [153] uses a complex vital bar for health, armor, stamina, energy, thirst (depicted as a waterdrop), and hunger (depicted as a stomach). The Long Dark [84] uses similar vital bar elements. In The Wizards [30], the health bar consists of a color-coded symbol, integrated on the character's gloves. Opponents' health bars in Borderlands [75] and Conan Exiles [70] are displayed above or in front of the opponents depending on their height. In Doom [88]

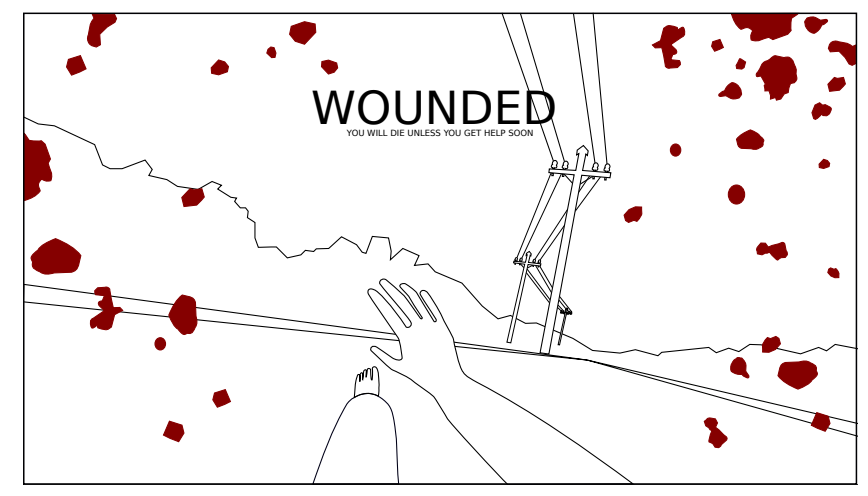

Figure 7: Examples of visual delegates addressing the perception of health. Vital signs (implicit): player character lying on the ground with protecting hand pose and tilted view indicating a painful collision or attack. Vital signs (explicit): red (blood) drops and text saying "Wounded".

Table 5: Visual delegates addressing sense of health and exemplary video games using these delegates. Additional use in other perceptions is marked with PRE for presence, PRO for proprioception, and HEA for health.

\begin{tabular}{|c|c|}
\hline Visual Delegate (Health) & Games \\
\hline \multicolumn{2}{|c|}{ Vital Signs (implicit) } \\
\hline Lowered/tilted view ${ }^{(\mathrm{PRO})}$ & {$[52,61,92,93]$} \\
\hline Protecting hand pose & {$[61]$} \\
\hline Blurred peripheral view & {$[52,93]$} \\
\hline Chromatic aberration/color grading & {$[137]$} \\
\hline Vignetting/tunnel vision (HEA) & {$[29,71,91,170]$} \\
\hline Regenerating equipment & {$[38,167]$} \\
\hline \multicolumn{2}{|c|}{ Vital Signs (explicit) } \\
\hline Health/vital bar & {$[46,70,84,144,153]$} \\
\hline (Pulsating) screen filters (HEA) & {$[35,51,71,160,162]$} \\
\hline Blood drops/scattered dark spots & {$[15,29,61,92]$} \\
\hline Colored screen edges (PRE) & {$[91,146,153]$} \\
\hline \multicolumn{2}{|c|}{ State of Mind (implicit) } \\
\hline Warm colored surrounding & {$[95]$} \\
\hline Bright light/chaotic shadows & {$[123]$} \\
\hline Blur & {$[67,116,117,123]$} \\
\hline Vignetting/tunnel vision (HEA) & {$[53]$} \\
\hline Yellow/red filter ${ }^{\text {HEA) }}$ & {$[116,117]$} \\
\hline \multicolumn{2}{|c|}{ State of Mind (explicit) } \\
\hline Text & {$[7,152]$} \\
\hline Depiction of brain that changes color & {$[67]$} \\
\hline
\end{tabular}

the screen flashes with a red, semi-transparent filter each time the character is hit. Steep [160] uses a grayscale filter when the player character bumps into trees while skiing to indicate a bad health condition. In Destiny 2 [29] the screen is fully covered with a distorted red filter if the received hit was powerful. Battlefield: Bad Company 2 [51] changes the color of the filter from red to dark gray when the 
vital condition of the player character is getting worse, comparable with different fill levels of a conventional health bar. A pulsating red screen filter appears in Alien: Isolation [35] and in Far Cry 3 [162] when the player character is unable to breath while diving. Rust [61] extends a red filter with blood drops at the screen edges (figure 7). Being hit by projectiles in Call of Duty: Modern Warfare 2 [92], the screen is filled with red, semi-transparent abstractions of blood drops which expand through the whole screen the more drastic the medical condition of the character aggravates (figure 1). In Dishonored 2 [15], the red blood drops of the opponents, compared to the player character's blood drops (both rendered on the HUD) differ in lightness to be able to assign them to the player or player character. After falling on ground from a great height in Destiny 2 [29], irregular dark gray spots are scattered on the HUD, similar to the blood drops visualization.

4.5.3 State of Mind (implicit). Radiating safety and serenity are addressed in BioShock Infinite [95] by using warm colors and a soft focus filter (or gaussian blur) on the whole environment. In Hellblade: Senua's Sacrifice [123], the player character suffers from severe psychosis and post-traumatic stress disorder. Delusions and anxieties are represented by visual effects such as chromatic aberration, excessive saturation of bright light sources, shadows that seem to twist and turn, or intense blurring of distant areas. In Amnesia: The Dark Descent [67], a blurry peripheral field of view delegates a threatening situation or a state of fear. The sensation of stress in Battlefield 1 [53] can be derived by a narrowed view with dark screen edges (vignetting) which appear when projectiles are hitting the character's closer surroundings. Stress in F.E.A.R. 2: Project Origin [117] is indicated by a yellow filter as well as a darkening and blurry view. In F.E.A.R. [116], tension and stress is addressed by using a red filter at the screen edges and a gentle blur with sharp vision only in the center of the field of view.

4.5.4 State of Mind (explicit). Thoughts of characters in video games are often transferred to the player by thinking aloud as a verbal form of communication with the player, e.g., applied in What Remains of Edith Finch [76]. A visual delegate to transport the character's thoughts to the player is text, which can be observed in Deadly Premonition [7] or The Vanishing of Ethan Carter [152]. Psychological conditions are visualized in Amnesia: The Dark Descent [67] with depictions of a brain changing its color on the HUD.

\section{DISCUSSION}

Our analysis shows that the mechanism of sensory substitution $[18,106]$ is applied in video games in derivative form, which we generally refer to as sensory delegation. We specifically investigated visual effects and techniques in CCVG and ascertained that these visual effects and techniques often function as visual delegates to address player perception via the visual sense. The nature of these perceptions we found are closely related to typical tasks in CCVG, i.e., exploring the game world (presence, movement), experiencing a whole new character (embodiment, proprioception), and entering combative confrontations with other entities (health).

The distinction between implicit and explicit delegates revealed interesting insights and has also sharpened the debate during the classification process. Each sub-perception we found is covered by at least one implicit and one explicit delegate, usually more. For instance, we found a huge variety of visual delegates (implicit and explicit) transporting the state of health after being injured which points out the importance of an omnipresent health information in particular games. We conclude that there is a sufficient number of delegates allowing game designers to replace explicit with implicit delegates or vice versa. This could help to reduce excessive use of explicit delegates, in favour of expert players, cf., Iacovides et al. [86], and to prevent delegates from being perceived as disruptive, cf., Fragoso [66].

During our analysis we also tried to subdivide perceptions with the concept of diegesis and found out that a few cases are not covered by this concept. For instance, non-narrative elements (e.g., vital bars) which are integrated into the game world (e.g., on the player character's gloves) and which can be seen by the character could be considered diegetic, cf., [30]. Elements which cannot be seen by the player character (non-diegetic), such as abstract visualizations of blood drops on the interface layer after being hit, can also be considered part of the narrative if they emerge in the game world, cf., [15]. In this sense, subdividing into implicit/explicit can bring forth comparable ambiguity. According to our investigations, subdividing perceptions into implicit/explicit was the best available conception because it does not only include what the player vs. player character can visually perceive but also the degree of complexity of how perception information is communicated to the player, i.e., condensed and easily accessible (explicit) or with the need to derive more complex information (implicit). However, this also leads to the conclusion that there is still room for further research to develop a concept for subdividing (visual) delegates even more meaningfully.

While the scope of our analysis is comprehensive, a set of 102 games is far from complete, and extending the data will clearly offer further insights. Looking at the time span of 28 years (analyzed games from the years 1992 to 2019), we can report an evolution process with regard to the visual presentation. For instance, health bars are increasingly replaced by more complex techniques, such as blood drops or vignetting, seemingly coincidentally with automatically regenerating health mechanics having replaced those based on power ups. Potentially, some older techniques could become extinct, while others are preserved or evolve further on. For instance, perceiving the player character from third-person perspective could vanish in favour of first-person perspective with virtual reality (VR) technology, whereas color-coding patterns have not changed. In addition, the number of visual delegates simultaneously presented to the player on the game interface have subjectively increased whereas their duration of exposition has subjectively decreased over time.

To the best of our knowledge, this is the first work that provides a systematic understanding of visual delegates which may lead to a more targeted application, e.g., optimized to reduce perceptual load for players. Perceptual load and, more generally, the actual user experience and how it might be affected (or not) by choosing particular delegates also needs a systematic analysis. Users studies could bring forth insights whether particular delegates can bring players and characters closer together, e.g., by evaluating x-ray vision or colored screen edges in terms of phenomena such as co-presence. Inducing stress in video games could be investigated by using visual 
delegates we collected for the sub-perception state of mind such as bright light, blur or color grading effects. Serious games refraining the use of visual effects typically applied in action-games could benefit from visual delegates when fictional aspects are reduced and serious aspects are emphasized. For instance, medical serious games could enhance empathy by visually delegating perception of pain from the perspective of a virtual patient. Delegates addressing different dimensions of embodiment could be used to visually perceive signs of old age to gain a better understanding of the elderly.

So far, we have specifically investigated visual delegates. However, the associated concept allows extensions to other modalities, especially auditory and tactile perception. To complete our classification and collection, auditory and tactile delegates must also be examined. For instance, muffled sound function as an auditory delegate for perceiving disorientation after being injured, comparable to a visual delegate which restricts the view with a tunnel vision. Vibrotactile feedback after pressing a button on a game controller to open a gate function as a tactile delegate for agency, comparable to a visual delegate that outlines the gate with a different color to indicate an interaction point. Extending our work and knowing about visual, auditory and tactile effects and possible extensions can help future game developers to argue for or against producing certain delegates.

\section{CONCLUSIONS AND FUTURE WORK}

We introduced the concept of visual delegates addressing visual transfer of player character sensation to player perception. As a first, we provided an overview of visual delegates and conducted a systematic analysis of 102 CCVG from the years 1992 to 2019 of different art styles and genres. Our collection and classification, although not complete, can be considered as a tool for game designers to find appropriate visual delegates for perceptions they want to trigger.

To further evolve this concept, future work has to evaluate our classification and collection with game designers and game developers to optimize how our results can be practically applied to systematically design visual delegates for enhancing player perceptions. Then, the theoretical concept of visual delegates should be explored in regard to further important aspects e.g., differences between delegates applied in VR, compared to non-VR games, the effect visual delegates elicit in player experience, and if visual delegates can contribute to bring player and player character closer together. We also suggest to consider delegating via other sensations and modalities, especially auditory and tactile perception and collect or create auditory and tactile delegates which can further enhance player perception. As a generalization, we propose visual, auditory, and tactile delegates as subcategories of an overall concept which we call sensory delegates that delegates player character sensation to the player experience.

\section{ACKNOWLEDGMENTS}

This work was carried out within the project ViTAWiN, funded by the German Federal Ministry of Education and Research (BMBF, FKZ 01PV18006). Konstantin Wegner also contributed to this work.

\section{REFERENCES}

[1] 2015, Inc. 2002. Medal of Honor: Allied Assault. Game [Microsoft Windows]. Electronic Arts, Redwood City, California, USA.

[2] 2K Australia. 2014. Borderlands: The Pre-Sequel. Game [Microsoft Windows, Mac OS X, Linux, PlayStation 3, PlayStation 4, Xbox 360, Xbox One, Shield Portable, Shield Tablet, Shield Android TV]. 2K Games, Novato, California, USA.

[3] 2K Boston and 2K Australia. 2007. BioShock. Game [Microsoft Windows, PlayStation 3, Xbox 360, Mac OS X, Linux]. 2K Games, Novato, California, USA.

[4] 2K Marin. 2010. BioShock 2. Game [Microsoft Windows, PlayStation 3, Xbox 360, Mac OS X]. 2K Games, Novato, California, USA.

[5] 343 Industries. 2012. Halo 4. Game [Xbox 360]. 343 Industries, Redmond, Washington, USA.

[6] 3D Realms. 1996. Duke Nukem 3D. Game [MS-DOS]. FormGen, Caledon, Ontario, Canada.

[7] Access Games. 2010. Deadly Premonition. Game [Microsoft Windows, PlayStation 3, Xbox 360]. Ignition Entertainment, Waltham Abbey, London, England.

[8] Farahnaz Ahmed, Joseph D. Cohen, Katherine S. Binder, and Claude L. Fennema. 2010. Influence of Tactile Feedback and Presence on Egocentric Distance Perception in Virtual Environments. In 2010 IEEE Virtual Reality Conference (VR). IEEE, Piscataway, New Jersey, USA, 195-202. https://doi.org/10.1109/VR.2010.5444791

[9] Sultan A. Alharthi, Olaa Alsaedi, Zachary O. Toups, Joshua Tanenbaum, and Jessica Hammer. 2018. Playing to Wait: A Taxonomy of Idle Games. In Proceedings of the 2018 CHI Conference on Human Factors in Computing Systems (Montreal QC, Canada) (CHI '18). Association for Computing Machinery, New York, NY, USA, 1-15. https://doi.org/10.1145/3173574.3174195

[10] Fraser Allison, Marcus Carter, Martin Gibbs, and Wally Smith. 2018. Design Patterns for Voice Interaction in Games. In Proceedings of the 2018 Annual Symposium on Computer-Human Interaction in Play (Melbourne, VIC, Australia) (CHI PLAY '18). Association for Computing Machinery, New York, NY, USA, 5-17. https://doi.org/10.1145/3242671.3242712

[11] Anastassia Andreasen, Niels Christian Nilsson, and Stefania Serafin. 2018. Agency Enhances Body Ownership Illusion of Being a Virtual Bat. In 2018 IEEE Conference on Virtual Reality and 3D User Interfaces (VR). IEEE, Piscataway, New Jersey, USA, 505-506. https://doi.org/10.1109/VR.2018.8446448

[12] Anastassia Andreasen, Niels Christian Nilsson, and Stefania Serafin. 2018. Spatial Asynchronous Visuo-Tactile Stimuli Influence Ownership of Virtual Wings. In 2018 IEEE Conference on Virtual Reality and 3D User Interfaces (VR). IEEE, Piscataway, New Jersey, USA, 503-504. https://doi.org/10.1109/VR.2018.8446569

[13] Ulrich Ansorge and Helmut Leder. 2011. Wahrnehmung und Aufmerksamkeit (Perception and Attention). VS Verlag für Sozialwissenschaften, Wiesbaden, 9-25. https://doi.org/10.1007/978-3-531-92094-8_1

[14] Arkane Studios. 2012. Dishonored. Game [Microsoft Windows, PlayStation 4, Xbox One]. Bethesda Softworks, Rockville, Maryland, USA.

[15] Arkane Studios. 2016. Dishonored 2. Game [Microsoft Windows, PlayStation 4, Xbox One]. Bethesda Softworks, Rockville, Maryland, USA.

[16] Halim Cagri Ates, Alexander Fiannaca, and Eelke Folmer. 2015. Immersive Simulation of Visual Impairments Using a Wearable See-through Display. In Proceedings of the Ninth International Conference on Tangible, Embedded, and Embodied Interaction (Stanford, California, USA) (TEI '15). ACM, New York, NY, USA, 225-228. https://doi.org/10.1145/2677199.2680551

[17] Benjamin Avery, Christain Sandor, and Bruce H. Thomas. 2009. Improving Spatial Perception for Augmented Reality X-Ray Vision. In 2009 IEEE Virtual Reality Conference. IEEE, Piscataway, New Jersey, USA, 79-82. https://doi.org/ 10.1109/VR.2009.4811002

[18] Paul Bach-y Rita and Stephen W. Kercel. 2003. Sensory Substitution and the Human-Machine Interface. Trends in Cognitive Sciences 7, 12 (2003), 541-546. https://doi.org/10.1016/j.tics.2003.10.013

[19] Henry Charlton Bastian. 1880. The Brain as an Organ of Mind. Vol. 29. Appleton, New York.

[20] Behaviour Interactive. 2016. Dead by Daylight. Game [Microsoft Windows, PlayStation 4, Xbox One, Nintendo Switch, Android, iOS]. 505 Games, Milan, Italy.

[21] Bethesda Game Studios. 2011. The Elder Scrolls V: Skyrim. Game [Microsoft Windows, PlayStation 3, PlayStation 4, Xbox 360, Xbox One, Nintendo Switch]. Bethesda Softworks, Rockville, Maryland, USA.

[22] Frank Biocca, Chad Harms, and Judee K. Burgoon. 2003. Toward a More Robust Theory and Measure of Social Presence: Review and Suggested Criteria. Presence: Teleoperators and Virtual Environments 12, 5 (2003), 456-480. https://doi.org/10. $1162 / 105474603322761270$

[23] Frank Biocca, Chad Harms, and Jennifer Gregg. 2001. The Networked Minds Measure of Social Presence: Pilot Test of the Factor Structure and Concurrent Validity. 4th Annual International Workshop on Presence, Philadelphia 4 (01 2001), $1-9$.

[24] Olaf Blanke and Thomas Metzinger. 2009. Full-Body Illusions and Minimal Phenomenal Selfhood. Trends in cognitive sciences 13, 1 (2009), 7-13. https: //doi.org/10.1016/j.tics.2008.10.003

[25] Blizzard Entertainment. 2016. Overwatch. Game [Microsoft Windows, PlayStation 4, Xbox One]. Blizzard Entertainment, Irvine, California, USA. 
[26] Emily Brown and Paul Cairns. 2004. A Grounded Investigation of Game Immersion. In CHI '04 Extended Abstracts on Human Factors in Computing Systems (Vienna, Austria) (CHI EA '04). Association for Computing Machinery, New York, NY, USA, 1297-1300. https://doi.org/10.1145/985921.986048

[27] Gerd Bruder, Frank Steinicke, and Phil Wieland. 2011. Self-Motion Illusions in Immersive Virtual Reality Environments. In 2011 IEEE Virtual Reality Conference. IEEE, Piscataway, New Jersey, USA, 39-46. https://doi.org/10.1109/VR.2011. 5759434

[28] Bungie. 2001. Halo: Combat Evolved. Game [Microsoft Windows, Mac OS X, Xbox]. Microsoft Game Studios, Redmond, Washington, USA.

[29] Bungie. 2017. Destiny 2. Game [Microsoft Windows, PlayStation 4, Xbox One]. Activision, Santa Monica, California, USA

[30] Carbon Studio. 2019. The Wizards: Enhanced Edition. Game [PlayStation 4 (VR)]. Carbon Studio, Chorzów, Poland.

[31] City Interactive. 2008. SAS: Secure Tomorrow. Game [Microsoft Windows]. City Interactive, Warsaw, Poland.

[32] City Interactive. 2013. Sniper: Ghost Warrior 2. Game [Microsoft Windows, PlayStation 3, Xbox 360]. City Interactive, Warsaw, Poland.

[33] Luciano R. Coutinho, Victor M. Galvão, Antônio de Abreu Batista, Bruno Roberto S. Moraes, and Márcio Regis M. Fraga. 2015. Organizational Gameplay: The Player as Designer of Character Organizations. International fournal of Com puter Games Technology 2015 (2015), 1-11. https://doi.org/10.1155/2015/731031

[34] Arthur D. Craig. 2002. How Do You Feel? Interoception: The Sense of the Physiological Condition of the Body. Nature reviews neuroscience 3, 8 (2002) 655-666. https://doi.org/10.1038/nrn894

[35] Creative Assembly. 2014. Alien: Isolation. Game [Microsoft Windows, Mac OS X, Linux, PlayStation 3, PlayStation 4, Xbox 360, Xbox One]. Saga, Shinagawa-ku, Tokyo, Japan.

[36] Crystal Dynamics. 2015. Rise of the Tomb Raider. Game [macOS, Microsoft Windows, PlayStation 4, Xbox 360, Xbox One, Linux, Stadia]. Square Enix, Shinjuku, Tokyo, Japan.

[37] Crytek. 2007. Crysis. Game [Microsoft Windows, PlayStation 3, Xbox 360] Electronic Arts, Redwood City, California, USA.

[38] Crytek. 2011. Crysis 2. Game [Microsoft Windows, PlayStation 3, Xbox 360]. Electronic Arts, Redwood City, California, USA

[39] Crytek. 2013. Crysis 3. Game [Microsoft Windows, PlayStation 3, Xbox 360]. Electronic Arts, Redwood City, California, USA.

[40] Danger Close Games. 2012. Medal of Honor: Warfighter. Game [Microsoft Windows, PlayStation 3, Xbox 360]. Electronic Arts, Redwood City, California USA.

[41] Demruth. 2013. Antichamber. Game [Microsoft Windows, Mac OS X, Linux] Demruth, Melbourne, Australia.

[42] DePaul University students. 2010. Octodad. Game [Microsoft Windows, Mac OS X, Linux]. Freeware, Chicago, Illinois, USA.

[43] Heather Desurvire and Dennis Wixon. 2018. Heuristic uncovered for Game User Researchers and game designers. In Games User Research, Anders Drachen, Pejman Mirza-Babaei, and Lennart E. Nacke (Eds.). Oxford University Press, Oxford, United Kingdom, Chapter 14, 217-256. https://doi.org/10.1093/oso/ 9780198794844.001.0001

[44] Ralf Dörner, Wolfgang Broll, Paul Grimm, and Bernhard Jung. 2013. Virtual und Augmented Reality (VR/AR): Grundlagen und Methoden der Virtuellen und Augmentierten Realität. Springer Vieweg, Berlin. https://doi.org/10.1007/978-3642-28903-3

[45] Anders Drachen, Pejman Mirza-Babaei, and Lennart E. Nacke. 2018. Games User Research. Oxford University Press, Oxford, United Kingdom. https://doi. org/10.1093/oso/9780198794844.001.0001

[46] Dreamworks Interactive. 1998. Trespasser. Game [Microsoft Windows]. Electronic Arts, Redwood City, California, USA.

[47] DreamWorks Interactive. 1999. Medal of Honor. Game [PlayStation]. Electronic Arts, Redwood City, California, USA.

[48] DreamWorks Interactive and Rebellion Developments. 2000. Medal of Honor: Underground. Game [PlayStation, Game Boy Advance]. Electronic Arts, Redwood City, California, USA.

[49] EA Canada and EA Seattle. 1997. Need for Speed II. Game [Microsoft Windows, PlayStation]. Electronic Arts, Redwood City, California, USA.

[50] EA DICE. 2008. Mirror's Edge. Game [Microsoft Windows, PlayStation 3, Xbox 360, iOS, Windows Phone]. Electronic Arts, Redwood City, California, USA.

[51] EA DICE. 2010. Battlefield: Bad Company 2. Game [Microsoft Windows, PlayStation 3, Xbox 360, iOS, Kindle Fire]. Electronic Arts, Redwood City, California, USA.

[52] EA DICE. 2011. Battlefield 3. Game [Microsoft Windows, PlayStation 4, Xbox One]. Electronic Arts, Redwood City, California, USA.

[53] EA DICE. 2016. Battlefield 1. Game [Microsoft Windows, PlayStation 4, Xbox One]. Electronic Arts, Redwood City, California, USA.

[54] EA Los Angeles. 2004. Medal of Honor: Pacific Assault. Game [Microsoft Windows]. Electronic Arts, Redwood City, California, USA.

[55] Ed Key and David Kanagat. 2013. Proteus. Game [Linux, Mac OS X, Microsoft Windows, PlayStation 3, PlayStation Vita]. Twisted Tree.
[56] Mie C. S. Egeberg, Stine L. R. Lind, Sule Serubugo, Denisa Skantarova, and Martin Kraus. 2016. Extending the Human Body in Virtual Reality: Effect of Sensory Feedback on Agency and Ownership of Virtual Wings. In Proceedings of the 2016 Virtual Reality International Conference (Laval, France) (VRIC '16). Association for Computing Machinery, New York, NY, USA, Article 30, 4 pages. https://doi.org/10.1145/2927929.2927940

[57] Eidos Montréal. 2011. Deus Ex: Human Revolution. Game [Mac OS X, Microsoft Windows, PlayStation 3, Wii U, Xbox 360]. Square Enix, Shinjuku, Tokyo, Japan.

[58] Eidos Montréal. 2014. Thief. Game [Mac OS X, Microsoft Windows, Nvidia Shield, PlayStation 3, PlayStation 4, Xbox 360, Xbox One]. Square Enix, Shinjuku, Tokyo, Japan.

[59] Eidos Montréal. 2016. Deus Ex: Mankind Divided. Game [Linux, macOS, Microsoft Windows, PlayStation 4, Xbox One]. Square Enix, Shinjuku, Tokyo, Japan.

[60] Evolution Studios. 2014. Driveclub. Game [PlayStation 4]. Sony Computer Entertainment, San Mateo, California, USA.

[61] Facepunch Studios. 2018. Rust. Game [Microsoft Windows, macOS]. Facepunch Studios, Walsall, England, UK.

[62] Erik Fagerholt and Magnus Lorentzon. 2009. Beyond the HUD - User Interfaces for Increased Player Immersion in FPS Games. Master's thesis. Chalmers University of Technology, Göteborg, Sweden. https://hdl.handle.net/20.500.12380/111921

[63] Kevin Fan, Jean-Marc Seigneur, Suranga Nanayakkara, and Masahiko Inami. 2016. Electrosmog Visualization Through Augmented Blurry Vision. In Proceedings of the 7th Augmented Human International Conference 2016 (Geneva, Switzerland) (AH '16). ACM, New York, NY, USA, Article 35, 2 pages. https: //doi.org/10.1145/2875194.2875203

[64] Fast Travel Games. 2018. Apex Construct. Game [Microsoft Windows (VR), Oculus Quest, Playstation 4 (VR)]. Fast Travel Games, Stockholm, Sweden.

[65] Clara Fernández-Vara. 2019. Introduction to Game Analysis (2 ed.). Routledge, 52 Vanderbilt Avenue, New York, NY 10017, USA. https://doi.org/10.4324/ 9781351140089

[66] Suely Fragoso. 2014. Interface Design Strategies and Disruptions of Gameplay: Notes from a Qualitative Study with First-Person Gamers. In Human-Computer Interaction. Applications and Services, Masaaki Kurosu (Ed.). Springer International Publishing, Cham, 593-603. https://doi.org/10.1007/978-3-319-07227-2

[67] Frictional Games. 2010. Amnesia: The Dark Descent. Game [Microsoft Windows, Mac OS X, Linux, PlayStation 4, Xbox One]. Frictional Games, Helsingborg, Sweden.

[68] FromSoftware. 2014. Dark Souls II. Game [Microsoft Windows, PlayStation 4, PlayStation 3, Xbox One, Xbox 360]. Bandai Namco Games, Minato-ku, Tokyo, Japan.

[69] FromSoftware. 2015. Bloodborne. Game [PlayStation 4]. Sony Computer Entertainment, San Mateo, California, USA.

[70] Funcom. 2018. Conan Exiles. Game [Microsoft Windows, PlayStation 4, Xbox 360]. Funcom, Oslo, Norway.

[71] Gaijin Entertainment. 2016. War Thunder. Game [Microsoft Windows, macOS, Linux, PlayStation 4, Xbox One]. Gaijin Entertainment, Moscow, Russia.

[72] Shaun Gallagher. 2000. Philosophical conceptions of the self: implications for cognitive science. Trends in cognitive sciences 4, 1 (2000), 14-21. https: //doi.org/10.1016/S1364-6613(99)01417-5

[73] Alexander R. Galloway. 2006. Gaming: Essays on Algorithmic Culture. Vol. 18. University of Minnesota Press, Minnesota, MN, USA.

[74] Gearbox Software. 2008. Brothers in Arms: Hell's Highway. Game [Microsoft Windows, PlayStation 3, Xbox 360]. Ubisoft, Montreuil, France.

[75] Gearbox Software. 2009. Borderlands. Game [Microsoft Windows, Mac OS X, PlayStation 3, Xbox 360]. 2K Games, Novato, California, USA.

[76] Giant Sparrow. 2017. What Remains of Edith Finch. Game [Microsoft Windows, PlayStation 4, Xbox One, Switch]. Annapurna Interactive, West Hollywood, California, USA.

[77] Barney G. Glaser and Anselm L. Strauss. 1967. The Discovery of Grounded Theory: Strategies for Qualitative Research. Aldine, Chicago.

[78] Erving Goffman. 1959. The Presentation of Self in Everyday Life. Anchor, Garden City, NY.

[79] Grin. 2009. Bionic Commando. Game [Microsoft Windows, PlayStation 3, Xbox 360]. Capcom, Chūō-ku, Osaka, Japan.

[80] Ground Shatter Ltd. 2019. RICO. Game [Microsoft Windows, PlayStation 4, Xbox One, Nintendo Switch]. Rising Star Games, Hitchin, Hertfordshire, UK.

[81] Chad Harms and Frank Biocca. 2004. Internal Consistency and Reliability of the Networked Minds - Measure of Social Presence. Seventh Annual International Workshop: Presence 7 (2004), 7.

[82] Hidden Path Entertainment. 2012. Counter-Strike: Global Offensive. Game [Microsoft Windows, Mac OS, Linux, PlayStation 3, Xbox 360]. Valve Corporation, Bellevue, Washington, USA.

[83] Sébastien Hillaire, Anatole Lécuyer, Rémi Cozot, and Géry Casiez. 2008. Depthof-Field Blur Effects for First-Person Navigation in Virtual Environments. IEEE Computer Graphics and Applications 28, 6 (2008), 47-55. https://doi.org/10.1109/ MCG.2008.113

[84] Hinterland Studio. 2017. The Long Dark. Game [Linux, Microsoft Windows, macOS, Xbox One, PlayStation 4]. Hinterland Studio, Vancouver, British 
Columbia, Canada.

[85] Human Head Studios. 2006. Prey. Game [Microsoft Windows, Mac OS X, Linux, Xbox 360]. 2K Games, Novato, California, USA.

[86] Ioanna Iacovides, Anna Cox, Richard Kennedy, Paul Cairns, and Charlene Jennett. 2015. Removing the HUD: The Impact of Non-Diegetic Game Elements and Expertise on Player Involvement. In Proceedings of the 2015 Annual Symposium on Computer-Human Interaction in Play (London, United Kingdom) (CHI PLAY '15). Association for Computing Machinery, New York, NY, USA, 13-22. https://doi.org/10.1145/2793107.2793120

[87] id Software. 1992. Wolfenstein 3D. Game [MS-DOS, Arcade, SNES, Jaguar, Classic Mac OS, Acorn Archimedes, 3DO, Apple IIGS, Game Boy Advance, Xbox, Linux, iOS, Xbox 360, PlayStation 3 (PSN), Android]. Apogee Software, Garland, Texas, USA.

[88] id Software. 1993. Doom. Game [MS-DOS]. id Software, Richardson, Texas, USA.

[89] id Software. 1994. Doom II. Game [MS-DOS]. GT Interactive Software, New York City, New York, USA.

[90] Wijnand A. IJsselsteijn, Huib de Ridder, Jonathan Freeman, and Steve E. Avons. 2000. Presence: concept, determinants, and measurement. In Human Vision and Electronic Imaging V, Bernice E. Rogowitz and Thrasyvoulos N. Pappas (Eds.) Vol. 3959. International Society for Optics and Photonics, SPIE, San Jose, CA United States, 520-529. https://doi.org/10.1117/12.387188

[91] Infinity Ward. 2005. Call of Duty 2. Game [Microsoft Windows, PlayStation 3, Xbox 360]. Activision, Santa Monica, California, USA.

[92] Infinity Ward. 2009. Call of Duty: Modern Warfare 2. Game [Microsoft Windows, PlayStation 3, Xbox 360]. Activision, Santa Monica, California, USA.

[93] Infinity Ward and Sledgehammer Games. 2011. Call of Duty: Modern Warfare 3. Game [Microsoft Windows, PlayStation 3, Xbox 360]. Activision, Santa Monica California, USA.

[94] Innerloop Studios. 2000. Project I.G.I. Game [Microsoft Windows]. Eidos Interactive, Wimbledon, Surrey, UK.

[95] Irretional Games. 2013. BioShock Infinite. Game [Microsoft Windows, Mac OS X, Linux, PlayStation 3, Xbox 360]. 2K Games, Novato, California, USA

[96] Colby Johanson, Carl Gutwin, and Regan L. Mandryk. 2017. The Effects of Navigation Assistance on Spatial Learning and Performance in a 3D Game. In Proceedings of the Annual Symposium on Computer-Human Interaction in Play (Amsterdam, The Netherlands) (CHI PLAY '17). Association for Computing Machinery, New York, NY, USA, 341-353. https://doi.org/10.1145/3116595. 3116602

[97] Sahib S. Khalsa and Rachel C. Lapidus. 2016. Can Interoception Improve the Pragmatic Search for Biomarkers in Psychiatry? Frontiers in Psychiatry 7 (2016), 121. https://doi.org/10.3389/fpsyt.2016.00121

[98] Konstantina Kilteni, Raphaela Groten, and Mel Slater. 2012. The Sense of Embodiment in Virtual Reality. Presence: Teleoperators and Virtual Environments 21, 4 (2012), 373-387. https://doi.org/10.1162/PRES_a_00124

[99] Tom Knoll. 2018. The think-aloud protocol. In Games User Research, Anders Drachen, Pejman Mirza-Babaei, and Lennart E. Nacke (Eds.). Oxford University Press, Oxford, United Kingdom, Chapter 12, 187-202. https://doi.org/10.1093/ oso/9780198794844.001.0001

[100] Andrey Krekhov, Sebastian Cmentowski, Katharina Emmerich, and Jens Krüger 2019. Beyond Human: Animals as an Escape from Stereotype Avatars in Virtual Reality Games. In Proceedings of the Annual Symposium on Computer-Human Interaction in Play (Barcelona, Spain) (CHI PLAY '19). Association for Computing Machinery, New York, NY, USA, 439-451. https://doi.org/10.1145/3311350. 3347172

[101] Andrey Krekhov, Sebastian Cmentowski, and Jens Krüger. 2019. The Illusion of Animal Body Ownership and Its Potential for Virtual Reality Games. In 2019 IEEE Conference on Games (CoG). IEEE, Piscataway, New Jersey, USA, 1-8. https://doi.org/10.1109/CIG.2019.8848005

[102] Krillbite Studio. 2014. Among the Sleep. Game [Microsoft Windows, Mac OS X, Linux, PlayStation 4, Xbox One, Nintendo Switch]. Krillbite Studio, Hamar Norway.

[103] Shringi Kumari, Sebastian Deterding, and Jonathan Freeman. 2019. The Role of Uncertainty in Moment-to-Moment Player Motivation: A Grounded Theory. In Proceedings of the Annual Symposium on Computer-Human Interaction in Play (Barcelona, Spain) (CHI PLAY '19). Association for Computing Machinery, New York, NY, USA, 351-363. https://doi.org/10.1145/3311350.3347148

[104] Anatole Lécuyer, Jean-Marie Burkhardt, Jean-Marie Henaff, and Stéphane Donikian. 2006. Camera Motions Improve the Sensation of Walking in Virtual Environments. In IEEE Virtual Reality Conference (VR 2006). IEEE, Piscataway, New Jersey, USA, 11-18. https://doi.org/10.1109/VR.2006.31

[105] Kwan Min Lee. 2006. Presence, Explicated. Communication Theory 14, 1 (01 2006), 27-50. https://doi.org/10.1111/j.1468-2885.2004.tb00302.x

[106] Charles Lenay, Olivier Gapenne, Sylvain Hanneton, Catherine Marque, and Christelle Genouëlle. 2003. Sensory substitution: Limits and perspectives. In Touching for knowing: Cognitive psychology of haptic manual perception, Yvette Hatwell, Arlette Streri, and Edouard Gentaz (Eds.). John Benjamins Publishing Company, Amsterdam, Netherlands, Chapter 16, 275-292. https://doi.org/10. 1075/aicr.53.22len

[107] Bigna Lenggenhager, Michael Mouthon, and Olaf Blanke. 2009. Spatial aspects of bodily self-consciousness. Consciousness and Cognition 18, 1 (2009), 110-117. https://doi.org/10.1016/j.concog.2008.11.003

[108] Ian Livingston. 2018. Post-launch in Game User Research. In Games User Research, Anders Drachen, Pejman Mirza-Babaei, and Lennart E. Nacke (Eds.). Oxford University Press, Oxford, United Kingdom, Chapter 4, 45-60. https: //doi.org/10.1093/oso/9780198794844.001.0001

[109] Stein C. Llanos. 2013. What Does the HUD Tell Us?: The Heads Up Display. In HCI International 2013 - Posters' Extended Abstracts, Constantine Stephanidis (Ed.), Vol. 374. Springer Berlin Heidelberg, Berlin, Heidelberg, 713-717. https: //doi.org/10.1007/978-3-642-39476-8_143

[110] Jeremy Long, Anthony Estey, David Bartle, Sven Olsen, and Amy A. Gooch. 2010. Catalyst: Seeing Through the Eyes of a Cat. In Proceedings of the Fifth International Conference on the Foundations of Digital Games (Monterey, California) (FDG '10). ACM, New York, NY, USA, 116-123. https://doi.org/10.1145/ 1822348.1822364

[111] Pedro Lopes, Alexandra Ion, Willi Mueller, Daniel Hoffmann, Patrik Jonell, and Patrick Baudisch. 2015. Proprioceptive Interaction. In Proceedings of the 33rd Annual ACM Conference on Human Factors in Computing Systems (Seoul, Republic of Korea) (CHI '15). ACM, New York, NY, USA, 939-948. https://doi. org/10.1145/2702123.2702461

[112] I. Scott MacKenzie. 2012. Human-Computer Interaction: An Empirical Research Perspective. Morgan Kaufmann, Burlington, Massachusetts, USA.

[113] Michael C. Medlock. 2018. The Rapid Iterative Test and Evaluation Method (RITE). In Games User Research, Anders Drachen, Pejman Mirza-Babaei, and Lennart E. Nacke (Eds.). Oxford University Press, Oxford, United Kingdom, Chapter 13, 201-215. https://doi.org/10.1093/oso/9780198794844.001.0001

[114] Betty J. Mohler, Heinrich H. Bülthoff, William B. Thompson, and Sarah H. CreemRegehr. 2008. A Full-body Avatar Improves Egocentric Distance Judgments in an Immersive Virtual Environment. In Proceedings of the 5th Symposium on Applied Perception in Graphics and Visualization (Los Angeles, California) (APGV '08). ACM, New York, NY, USA, 194. https://doi.org/10.1145/1394281.1394323

[115] Betty J. Mohler, Sarah H. Creem-Regehr, and William B. Thompson. 2006. The Influence of Feedback on Egocentric Distance Judgments in Real and Virtual Environments. In Proceedings of the 3rd Symposium on Applied Perception in Graphics and Visualization (Boston, Massachusetts, USA) (APGV'06). Association for Computing Machinery, New York, NY, USA, 9-14. https://doi.org/10.1145/ 1140491.1140493

[116] Monolith Productions. 2005. F.E.A.R. Game [Microsoft Windows, PlayStation 3, Xbox 360]. Vivendi Universal Games, Los Angeles, California, USA.

[117] Monolith Productions. 2009. F.E.A.R. 2: Project Origin. Game [Microsoft Windows, PlayStation 3, Xbox 360]. Warner Bros. Games, Burbank, California, USA.

[118] Namco. 2004. Katamari Damacy. Game [PlayStation 2, Microsoft Windows, Nintendo Switch]. Namco, Ōta, Tokyo, Japan.

[119] Naughty Dog. 2007. Uncharted: Drake's Fortune. Game [PlayStation 3, PlayStation 4]. Sony Computer Entertainment, San Mateo, California, USA.

[120] Naughty Dog. 2013. The Last of Us. Game [PlayStation 3, PlayStation 4]. Sony Computer Entertainment, San Mateo, California, USA.

[121] Neversoft. 2001. Tony Hawk's Pro Skater 3. Game [Microsoft Windows, Mac OS X, Playstation, PlayStation 2, Xbox, Game Boy Color, GameCube, Game Boy Advance, Nintendo 64]. Activision, Santa Monica, California, USA.

[122] Pavlos Nicolaou, Michael Loizou, and Fernando Loizides. 2016. Stroke Event Simulator Using Virtual Reality. In 2016 8th International Conference on Games and Virtual Worlds for Serious Applications (VS-GAMES). IEEE, Piscataway, New Jersey, USA, 1-2. https://doi.org/10.1109/VS-GAMES.2016.7590368

[123] Ninja Theory. 2017. Hellblade: Senua's Sacrifice. Game [Microsoft Windows, PlayStation 4, Xbox One, Switch]. Ninja Theory, Cambridge, England, UK.

[124] NovaLogic, Climax Group, Rebellion Developments, and Aspyr. 2003. Delta Force: Black Hawk Down. Game [Microsoft Windows, Mac OS X, PlayStation 2, Xbox]. NovaLogic, Malibu, California, USA.

[125] Catherine S. Oh, Jeremy N. Bailenson, and Gregory F. Welch. 2018. A Systematic Review of Social Presence: Definition, Antecedents, and Implications. Frontiers in Robotics and AI 5, 114 (2018), 35. https://doi.org/10.3389/frobt.2018.00114

[126] Janne Paavilainen. 2018. Heuristic evaluation of playability: Examples from social games research and free-to-play heuristics. In Games User Research, Anders Drachen, Pejman Mirza-Babaei, and Lennart E. Nacke (Eds.). Oxford University Press, Oxford, United Kingdom, Chapter 15, 257-279. https://doi. org/10.1093/oso/9780198794844.001.0001

[127] Margaree Peacocke, Robert J. Teather, Jacques Carette, and I. Scott MacKenzie. 2015. Evaluating the Effectiveness of HUDs and Diegetic Ammo Displays in First-person Shooter Games. In 2015 IEEE Games Entertainment Media Conference (GEM). IEEE, Piscataway, New Jersey, USA, 1-8. https://doi.org/10.1109/GEM. 2015.7377211

[128] Lane Phillips, Brian Ries, Michael Kaeding, and Victoria Interrante. 2010. Avatar Self-Embodiment Enhances Distance Perception Accuracy in Non-Photorealistic Immersive Virtual Environments. In 2010 IEEE Virtual Reality Conference (VR). 
IEEE, Piscataway, New Jersey, USA, 115-118. https://doi.org/10.1109/VR.2010. 5444802

[129] Steven A. Prescott and Stéphanie Ratté. 2017. Somatosensation and Pain. In Conn's Translational Neuroscience, P. Michael Conn (Ed.). Academic Press, San Diego, Chapter 23, 517-539. https://doi.org/10.1016/B978-0-12-802381-5.00037-

[130] Rebellion Developments. 2010. Aliens vs. Predator. Game [Microsoft Windows, PlayStation 3, Xbox 360]. Sega, Shinagawa-ku, Tokyo, Japan.

[131] Refraction Games. 2000. Codename Eagle. Game [Microsoft Windows]. TakeTwo Interactive, New York City, New York, USA.

[132] William Renthal. 2015. Pain Genetics. In Rosenberg's Molecular and Genetic Basis of Neurological and Psychiatric Disease (5 ed.), Roger N. Rosenberg and Juan M. Pascual (Eds.). Academic Press, Boston, Chapter 90, 1089-1100. https: //doi.org/10.1016/B978-0-12-410529-4.00090-5

[133] Retro Studios and Nintendo. 2002. Metroid Prime. Game [GameCube, Wii]. Nintendo, Kyoto, Japan.

[134] Brian Ries, Victoria Interrante, Michael Kaeding, and Lane Phillips. 2009. Analyzing the Effect of a Virtual Avatar's Geometric and Motion Fidelity on Ego-centric Spatial Perception in Immersive Virtual Environments. In Proceedings of the 16th ACM Symposium on Virtual Reality Software and Technology (Kyoto, Japan) (VRST '09). ACM, New York, NY, USA, 59-66. https://doi.org/10.1145/1643928.1643943

[135] Rockstar North. 2008. Grand Theft Auto IV. Game [PlayStation 3, Xbox 360 Microsoft Windows]. Rockstar Games, New York City, New York, USA.

[136] Rockstar North. 2013. Grand Theft Auto V. Game [Microsoft Windows, PlayStation 3, PlayStation 4, Xbox 360, Xbox One]. Rockstar Games, New York City, New York, USA.

[137] Rockstar Studios. 2018. Red Dead Redemption 2. Game [PlayStation 4, Xbox One, Microsoft Windows, Stadia]. Rockstar Games, New York City, New York, USA

[138] Mirweis Sangin. 2018. Observing the player experience: The art and craft of observing and documenting Games User Research. In Games User Research Anders Drachen, Pejman Mirza-Babaei, and Lennart E. Nacke (Eds.). Oxford University Press, Oxford, United Kingdom, Chapter 11, 175-188. https://doi. org/10.1093/oso/9780198794844.001.0001

[139] SCE Japan Studio. 2005. Shadow of the Colossus. Game [PlayStation 2]. Sony Computer Entertainment, San Mateo, California, USA.

[140] Jesse Schell. 2008. The Art of Game Design: A book of lenses. Morgan Kaufmann, Burlington, Massachusetts, USA.

[141] Jonas Schild, Liane Bölicke, Joseph J. LaViola Jr., and Maic Masuch. 2013. Creating and Analyzing Stereoscopic 3D Graphical User Interfaces in Digital Games. In Proceedings of the SIGCHI Conference on Human Factors in Computing Systems (Paris, France) (CHI '13). ACM, New York, NY, USA, 169-178. https://doi.org/10.1145/2470654.2470678

[142] Jonas Schild and Maic Masuch. 2012. Designing Stereoscopic Information Visualization for 3D-TV: What can we can learn from S3D Gaming?. In Stereoscopic Displays and Applications, Vol. 23. SPIE, Bellingham, Washington, USA, 12. https://doi.org/10.1117/12.911967

[143] Mel Slater, Amela Sadagic, Martin Usoh, and Ralph Schroeder. 2000. SmallGroup Behavior in a Virtual and Real Environment: A Comparative Study. Presence: Teleoperators and Virtual Environments 9, 1 (2000), 37-51. https: //doi.org/10.1162/105474600566600

[144] Sledgehammer Games. 2017. Call of Duty: WWII. Game [Microsoft Windows, PlayStation 4, Xbox One]. Activision, Santa Monica, California, USA.

[145] Sloclap. 2019. Absolver. Game [Microsoft Windows, PlayStation 4, Xbox One] Devolver Digital, Austin, Texas, USA.

[146] Square Enix. 2019. Left Alive. Game [Microsoft Windows, PlayStation 4]. Square Enix, Shinjuku, Tokyo, Japan.

[147] Stainless Games. 1997. Carmageddon. Game [MS-DOS, Microsoft Windows, Mac OS, PlayStation, Nintendo 64, Game Boy Color, iOS, Android]. Sales Curve Interactive, London, UK.

[148] Christopher Stifter, Sarah Edenhofer, and Sebastian von Mammen. 2016. Come Fly with Me-Perceive the World through a Mosquito's Senses. In 2016 8th International Conference on Games and Virtual Worlds for Serious Applications (VSGAMES). IEEE, Piscataway, New Jersey, USA, 1-4. https://doi.org/10.1109/VSGAMES.2016.7590341

[149] Survios. 2018. Sprint Vector. Game [Microsoft Windows (VR)]. Survios, Los Angeles, California, USA.

[150] Ron Tamborini and Paul Skalski. 2006. The Role of Presence in the Experience of Electronic Games. In Playing Video Games: Motives, Responses, and Consequence,
Peter Vorderer and Jennings Bryant (Eds.). Routledge, New York, NY, USA, Chapter 16, 225-240. https://doi.org/10.4324/9780203873700

[151] Techland. 2015. Dying Light. Game [Microsoft Windows, Mac OS X, Linux, PlayStation 4, Xbox One]. Warner Bros. Interactive Entertainment, Burbank, California, USA.

[152] The Astronauts. 2014. The Vanishing of Ethan Carter. Game [Microsoft Windows, PlayStation 4, Xbox One]. The Astronauts, Warsaw, Poland.

[153] The Astronauts. 2018. The Forest. Game [Microsoft Windows, PlayStation 4]. Endnight Games, Vancouver, British Columbia, Canada.

[154] The Fullbright Company and BlitWorks. 2013. Gone Home. Game [iOS, Linux, Mac OS X, Microsoft Windows, Nintendo Switch, PlayStation 4, Xbox One]. The Fullbright Company, Portland, Oregon, USA.

[155] Thekla, Inc. 2016. The Witness. Game [iOS, macOS, Microsoft Windows, Nvidia Shield, PlayStation 4, Xbox One]. Thekla.

[156] Zachary O. Toups, Nicolas Lalone, Sultan A. Alharthi, Hitesh Nidhi Sharma, and Andrew M. Webb. 2019. Making Maps Available for Play: Analyzing the Design of Game Cartography Interfaces. ACM Trans. Comput.-Hum. Interact. 26, 5, Article 30 (July 2019), 43 pages. https://doi.org/10.1145/3336144

[157] Treyarch. 2008. Call of Duty: World at War. Game [Microsoft Windows, PlayStation 3, Wii, Xbox 360]. Activision, Santa Monica, California, USA.

[158] Tripwire Interactive. 2013. Red Orchestra: Ostfront 41-45. Game [Linux, Mac OS X, Microsoft Windows]. Bold Games, Minnetonka, Minnesota, USA.

[159] John C. Tuthill and Eiman Azim. 2018. Proprioception. Current Biology 28, 5 (2018), 194-203. https://doi.org/10.1016/j.cub.2018.01.064

[160] Ubisoft Annecy. 2016. Steep. Game [Microsoft Windows, PlayStation 4, Xbox One]. Ubisoft, Montreuil, France.

[161] Ubisoft Montreal. 2009. Assassin's Creed II. Game [PlayStation 3, Xbox 360, Microsoft Windows, Mac OS X, PlayStation 4, Xbox One]. Ubisoft, Montreuil, France.

[162] Ubisoft Montreal. 2012. Far Cry 3. Game [Microsoft Windows, PlayStation 3, PlayStation 4, Xbox 360, Xbox One]. Ubisoft, Montreuil, France.

[163] Ubisoft Montreal. 2014. Far Cry 4. Game [Microsoft Windows, PlayStation 3, PlayStation 4, Xbox 360, Xbox One]. Ubisoft, Montreuil, France.

[164] Ubisoft Montreal. 2016. Far Cry Primal. Game [Microsoft Windows, PlayStation 4, Xbox One]. Ubisoft, Montreuil, France.

[165] Ubisoft Montreal. 2017. For Honor. Game [Microsoft Windows, PlayStation 4, Xbox One]. Ubisoft, Montreuil, France.

[166] Ubisoft Montreal. 2018. Far Cry 5. Game [Microsoft Windows, PlayStation 4, Xbox One]. Ubisoft, Montreuil, France.

[167] Unknown Worlds Entertainment. 2018. Subnautica. Game [Microsoft Windows, Mac OS X, PlayStation 4, Xbox One]. Unknown Worlds Entertainment, San Francisco, California, USA

[168] Valve Corporation. 1998. Half-Life. Game [Microsoft Windows, Mac OS X, Linux, PlayStation 2]. Sierra Studios, Los Angeles, California, USA.

[169] Valve Corporation. 2004. Half-Life 2. Game [Microsoft Windows, Mac OS X, Linux, PlayStation 3, Xbox, Xbox 360, Android]. Valve Corporation, Bellevue, Washington, USA.

[170] Valve South. 2010. Left 4 Dead. Game [Microsoft Windows, Mac OS, Xbox 360]. Valve Corporation, Bellevue, Washington, USA.

[171] Sebastian von Mammen, Andreas Knote, and Sarah Edenhofer. 2016. Cyber Sick but Still Having Fun. In Proceedings of the 22Nd ACM Conference on Virtual Reality Software and Technology (Munich, Germany) (VRST '16). ACM, New York, NY, USA, 325-326. https://doi.org/10.1145/2993369.2996349

[172] Fabian Werfel, Roman Wiche, Jochen Feitsch, and Christian Geiger. 2016. Empathizing Audiovisual Sense Impairments: Interactive Real-Time Illustration of Diminished Sense Perception. In Proceedings of the 7th Augmented Human International Conference 2016 (Geneva, Switzerland) (AH '16). ACM, New York, NY, USA, Article 15, 8 pages. https://doi.org/10.1145/2875194.2875226

[173] White Paper Games. 2014. Ether One. Game [Microsoft Windows, PlayStation 4]. White Paper Games, Manchester, UK.

[174] Bob G. Witmer and Michael J. Singer. 1998. Measuring Presence in Virtual Environments: A Presence Questionnaire. Presence: Teleoperators and Virtual Environments 7, 3 (1998), 225-240. https://doi.org/10.1162/105474698565686

[175] Jason Wuertz, Sultan A. Alharthi, William A. Hamilton, Scott Bateman, Carl Gutwin, Anthony Tang, Zachary Toups, and Jessica Hammer. 2018. A Design Framework for Awareness Cues in Distributed Multiplayer Games. In Proceedings of the 2018 CHI Conference on Human Factors in Computing Systems (Montreal QC, Canada) (CHI '18). Association for Computing Machinery, New York, NY, USA, 1-14. https://doi.org/10.1145/3173574.3173817 